\begin{tabular}{|c|l|}
\hline Title & $\begin{array}{l}\text { siRNA gel solin knockdown induces epithelial-mesenchymal transition with a cadherin switch in human mammary } \\
\text { epithelial cells }\end{array}$ \\
\hline Author(s) & $\begin{array}{l}\text { Tanaka, Hiroki; Shirkoohi, Reza; Nakagawa, Koji; Qiao, Hongjiang; Fujita, Hisakazu; Okada, Futoshi; Hamada, Jun- } \\
\text { ichi; Kuzumaki, Satoshi; Takimoto, Masato; Kuzumaki, Noboru }\end{array}$ \\
\hline Citation & $\begin{array}{l}\text { International Journal of Cancer, 118/7), 1680-1691 } \\
\text { https://doi.org/10.1002/jc.21559 }\end{array}$ \\
\hline Issue Date & 2005-10-10 \\
\hline Doc URL & http://hdl.handle.net/2115/715 \\
\hline Rights & Copyright (c) 2005 Wiley-Liss, Inc \\
\hline Type & article (author version) \\
\hline File Information & NK05T an.pdf \\
\hline
\end{tabular}

Instructions for use 
Int. J. Cancer Published Online: 10 Oct 2005

\section{siRNA gelsolin knockdown induces epithelial-mesenchymal transition with a cadherin switch in human mammary epithelial cells}

Hiroki Tanaka ${ }^{1 \#}$, Reza Shirkoohi ${ }^{1 \#}$, Koji Nakagawa ${ }^{1}$, Hongjiang Qiao ${ }^{1}$, Hisakazu Fujita $^{3}$, Futoshi Okada ${ }^{4}$, Jun-ichi Hamada ${ }^{2}$, Satoshi Kuzumaki ${ }^{1}$, Masato Takimoto ${ }^{1}$, and Noboru Kuzumaki ${ }^{1 *}$

1. Division of Cancer Gene Regulation, Research Section of Disease Control, 2. Division of Cancer-Related Genes, Research Section of Molecular Pathogenesis, Institute for Genetic Medicine, Hokkaido University, Sapporo 060-0815, 3. Department of Structural Analysis, Research Institute, National Cardiovascular Center, Osaka 565-8565, 4. Department of Biomolecular Function, Graduate School of Medical Science, Yamagata University, Yamagata 990-9585, Japan

Short title: siRNA gelsolin-induced EMT

*Correspondence to: Division of Cancer Gene Regulation, Institute for Genetic Medicine, Hokkaido University, Kita-15, Nishi-7, Kita-Ku, Sapporo 060-0815, Japan. FAX: +81-11-706-7869. E-mail: kuzumaki@igm.hokudai.ac.jp

${ }^{\#}$ The first two authors contributed equally to this paper.

Abbreviations used: EMT: epithelial-mesenchymal transition, siRNA: small interfering RNA, shRNA: short hairpin RNA, PCR: polymerase chain reaction, GFP: green fluorescent protein, mAb: monoclonal antibody, FITC: fluorescein, pAb: polyclonal antibody, ERK: extracellular signal-regulated kinase, PI3K: phosphatidylinositol 3-kinase, GSK3: glycogen synthase kinase-3, SDS: sodium dodecyl sulfate, PBS: phosphate-buffered saline, TBS: Tris-buffered saline, BSA: bovine serum albumin, RT-RCR: reverse transcription-PCR, SRF: serum response factor, GAPDH: glyceraldehyde-3-phosphate dehydrogenase

Category: Cancer Cell Biology 


\section{Summary/Abstract}

Epithelial-mesenchymal transition (EMT) describes a process occurring during development and oncogenesis by which epithelial cells obtain fibroblast-like properties and show reduced cell adhesion and increased motility. In this report we demonstrated typical EMT in human mammary epithelial MCF10A siRNA gelsolin knockdown cells. EMT was characterized by fibroblastic morphology, loss of contact inhibition and focus formation in monolayer growth, enhanced motility and invasiveness in vitro, increased actin filaments, overexpression of RAC, activation of both ERK and AKT, inactivation of GSK3, conversion of cadherin from the E- to $\mathrm{N}$-type, and induction of the transcription factor Snail. These results suggested that gelsolin functions as a switch that controls $\mathrm{E}-$ and $\mathrm{N}$-cadherin conversion via Snail, and demonstrated that its knockdown leads to EMT in human mammary epithelial cells and possibly to the development of human mammary tumors.

Key words: actin-regulatory protein, small interfering RNA, EMT

\section{Introduction}

Gelsolin is a widely distributed actin-regulatory protein that can nucleate and sever actin filaments and cap the barbed end of filaments, processes that may play an important role in cell motility. ${ }^{1,2}$ Additionally, gelsolin is involved in controlling cell morphology, growth and apoptosis. ${ }^{2,3}$ Previously, we and other groups reported that the expression of gelsolin is frequently silenced in various cancers including breast, ${ }^{4,5}$, stomach, ${ }^{6}$ colon, ${ }^{7}$ urinary bladder, ${ }^{8}$ lung, ${ }^{9}$ prostate, ${ }^{10}$ kidney ${ }^{11}$ and ovarium, ${ }^{12}$ both in cell lines and human tissue tumors. Chaponnier and Gabbiani indicated that no staining for gelsolin was detectable in carcinoma cells with the exception of remaining myoepithelial cells. ${ }^{4}$ The frequency of gelsolin deficiency increases significantly with progression from atypical ductal hyperplasia to ductal carcinoma in situ to invasive breast carcinoma. ${ }^{5}$

On the other hand, although about one-third of lung tumor blocks in stage I non-small cell lung cancers showed no gelsolin expression, the remainder showed significant gelsolin expression that increased compared with that seen in normal lung mucosa or stroma cells. ${ }^{13}$ Furthermore, a fraction of these showed high levels of expression that was correlated with lymphatic invasion. Rao et al. observed reduced gelsolin expression in premalignant and malignant lesions of urothelial carcinoma, but increased expression in the transition from non-invasive to invasive tumors, as determined by tissue microarray analysis. ${ }^{14}$ They argued that whereas decreased expression of gelsolin occurs at the early stages of malignant transformation, increased gelsolin expression probably plays a critical role in converting the superficial tumor to an invasive tumor. Thor et al. showed that overexpression of gelsolin, epidermal growth factor receptor and ERBB-2 protein significantly predicted poor clinical outcome of breast cancers, as determined by univariate and multivariate analyses. ${ }^{15}$ They hypothesized that this was due to the role of gelsolin might play in mediating motility and invasion.

In fibroblasts, overexpression of gelsolin resulted in a reduction in filamentous actin, which could result in reduced substrate-adhesive properties and increased motility rates in chemoattractant or wound healing experiments. ${ }^{16}$ Gelsolin 
concentration alone does not apparently determine migratory capacity, but the $\mathrm{Ca}^{2+}$-dependent actin severing activity of free gelsolin appears to be a major determinant of cell migration. ${ }^{17}$ In epithelial cells, although gelsolin-transfected Madin-Darby canine kidney (MDCK) cells showed no reduction in stress fibers or total actin levels, expression of ectopic gelsolin in MDCK or human embryonic kidney (HEK293T) cells promoted invasion into collagen type-I. ${ }^{18}$ In contrast, we previously proposed that gelsolin can function as a tumor suppressor, since overexpression of wild-type gelsolin inhibited the growth of colon, bladder and lung cancer cell lines in in vitro and in vivo. ${ }^{7,8,19-21}$ We also showed that one mechanism accounting for the inhibition of cell proliferation and tumorigenicity was related to gelsolin suppressing the activation of protein kinase $\mathrm{Cs}$ involved in phospholipid signaling pathways. ${ }^{21}$ Furthermore, we demonstrated that transfectants expressing ectopic gelsolin of a highly metastatic murine melanoma cell line, B16-BL6, exhibited retardation of cell spreading, reduced chemotactic migration to fibronectin and suppressed lung colonization in a spontaneous metastasis assay. ${ }^{22}$

Further investigations are required concerning the role of gelsolin in tumor progression in an effort to delineate whether reduced and/or increased gelsolin levels in tumors reflect a direct causal relationship with tumorigenesis. Methods for expressing small interfering (si)RNAs in cells in culture and in vivo using diced siRNA or short hairpin RNA (shRNA) expressing vectors have been developed and are being used to establish the functions of specific proteins in various cell types. ${ }^{23}$ In an effort to determine whether reduced cytosolic gelsolin levels trigger changes in cellular behavior, we employed an siRNA approach utilizing the human immortalized mammary epithelial cell line MCF10A to examine whether gelsolin-knockdown promoted enhanced motility and invasiveness as tumor cells.

\section{Materials and methods}

\section{Cell lines}

MCF10A, a human immortalized mammary epithelial cell line ${ }^{24}$ was obtained from the American Type Culture Collection. Cells were grown in Mammary Epithelial Growth Medium (Serum-free, Clonetics, Walkersville, MD) supplemented with 100 $\mathrm{ng} / \mathrm{ml}$ cholera toxin (Calbiochem, San Diego, CA). All MCF10A, subculture cells generated by electroporation, and derivative cells were propagated at $37^{\circ} \mathrm{C}$ in a humidified atmosphere containing $5 \% \mathrm{CO}_{2}$. Morphology was determined by allowing cells to grow to subconfluence in 12-well dishes at a density of $4 \times 10^{4}$ cells per well.

\section{Expression plasmids}

The LKCG expression plasmid containing human cytoplasmic gelsolin was a kind gift from D. Kwiatkowski (Harvard Medical School, Boston). After a coding sequence of human gelsolin was amplified by PCR using the LKCG as a template, the resulting PCR fragment was digested by EcoRI and Xhol, and subcloned into pCMV-3xFLAG which was generated by inserting a fragment of $3 \times F L A G$ tag into pcDNA3.1(+) neo (Invitrogen, Carlsbad, CA), the N-terminal FLAG-tagged human gelsolin expression vector pCMV-3xFLAG(neo)-hGSN and a control vector pCMV-3xFLAG(neo) were constructed. All plasmids were purified using a Plasmid midi kit (QIAGEN, Hilden, Germany) prior to transfection. 


\section{RNA interference}

To knock down gelsolin expression, we used two different siRNA methods; siRNA generated using Dicer enzyme "diced-siRNA" ${ }^{25}$, and short hairpin RNA (shRNA) expression vectors. Firstly, siRNA was generated using a Dicer siRNA generation kit (Gene Therapy Systems, San Diego, CA) according to the manufacturer's protocol. Forward and reverse PCR primers were designed such that they would generate PCR products between 398 downstream and 1,046 downstream of the first ATG of human gelsolin CDNA. The forward and reverse primer sequences used were 5'-GCG TAA TAC GAC TCA CTA TAG GGA GAA TGT GCA GCT GGA TGA CTA G-3' and 5'-GCG TAA TAC GAC TCA CTA TAG GGA GAT AAG CTT GCC TTT CCA GAC AAA G-3', respectively. The gelsolin sequence in the primer was flanked on the $5^{\prime}$ ends with 20 nucleotides from the T7 RNA polymerase promoter. Human gelsolin-cDNAs were used as the template for PCR. Following PCR, the products (586 bp) were used as templates for in vitro transcription using T7 RNA polymerase, which resulted in the formation of dsRNA gelsolin-related fragments. The resulting material was treated with DNase to remove the DNA template and RNase to remove any ssRNA. The resulting gelsolin dsRNA was then cleaved into small segments of diced-siRNA (20 22 bp) using the RNA Dicer enzyme. Green fluorescent protein (GFP) diced-siRNA (Gene Therapy Systems) targeted to GFP was prepared as a negative control. Secondly, we designed shRNA to interfere with gelsolin expression, referring to technical information by Ambion (Austin, TX, USA). A 19 nucleotide sequence (5'-CAA TGG CGA CTG CTT CAT C-3') corresponding to a sequence located 631 nucleotides downstream of the first ATG of the human gelsolin open reading frame sequence was inserted into the pSilencer 3.1-H1 hygro vector (Ambion). The resulting gelsolin shRNA vector (pSGSN3) expresses shRNA under control of the human $\mathrm{H} 1$ promoter. In order to be certain that these sequences would not interfere with other genes, a BLAST search confirmed that the selected oligonucleotide sequence did not possess homology to any other genes. An unrelated control shRNA vector (pSGFP), which would target the GFP DNA sequence (5'-GGT TAT GTA CAG GAA CGC A-3') with no significant match in the complete human genome, was also prepared under similar conditions.

\section{Transfection and generation of stable cell lines}

Experiments were performed using Nucleofector technology (Amaxa Biosystems, Gaithersburg, MD). The electroporation was performed according to the manufacturer's instructions. Briefly, for each reaction, $5 \times 10^{5} \mathrm{MCF} 10 \mathrm{~A}$ cells were harvested by trypsin-EDTA and mixed with a total of $3 \mu \mathrm{g}$ of expression vector plasmid DNA (pCMV-3xFLAG(neo)-hGSN or pCMV-3xFLAG(neo)) for overexpression, and 250 ng diced-siRNA or $3 \mu \mathrm{g}$ shRNA expression vector (pSGSN3 or pSGFP) for knockdown expression in $100 \mu \mathrm{l}$ of culture medium. Following electroporation, samples were transferred into 12 -well plates and incubated at $37^{\circ} \mathrm{C}$ in $5 \% \mathrm{CO}_{2}$. Stable clones were established by treatment with medium containing 100 $\mu \mathrm{g} / \mathrm{ml} \mathrm{G} 418$ for 7 days for overexpression clones, or by treatment with medium containing $25 \mu \mathrm{g} / \mathrm{ml}$ hygromycin for 7 days for shRNA expression vectors, and by limiting dilution methods.

\section{Reagents and antibodies}

Rhodamine-phalloidin was purchased from Molecular Probes, Inc. (Eugene, OR). 
The primary antibodies used included mouse monoclonal antibody (mAb) to human actin (Chemicon international, Temecula, $\mathrm{CA}$ ), mouse $\mathrm{mAb}$ to human gelsolin (GS-2C4, Sigma-Aldrich, St. Louis, MO), mAb to human RAC (Transduction Laboratories, Lexington, KY), mouse mAb to human E-cadherin (Transduction Laboratories), mouse mAb to human $\mathrm{N}$-cadherin (Zymed laboratories, San Francisco, CA), Fluorescein (FITC)-conjugated goat anti-mouse IgG+lgM (Jackson Immuno-Research Laboratories, West Grove, PA), mouse mAb to human RAS \#35, ${ }^{26}$ mouse mAbs to human alpha-, beta- and gamma-catenins (Transduction Laboratories), rabbit polyclonal antibody (pAb) to human ERK-1 and ERK-2, rabbit $\mathrm{pAb}$ to human phosphorylated ERK (Promega, Madison, WI), rabbit pAb to human PI3K (Transduction Laboratories), rabbit pAbs to human total AKT and phosphorylated AKT (Ser 473), and rabbit pAb to human total glycogen synthase kinase-3 (GSK3)ß and phosphorylated GSK3ß (Ser9) (Cell Signalling Technology, Beverly, MA), and rabbit affinity isolated antibody to human fibronectin (Sigma-Aldrich). Secondary antibodies used for Western blotting were peroxidase-conjugated rabbit or goat anti-mouse IgG (Jackson Immuno-Research Laboratories) or anti-rabbit IgG (Biosource International, Rockville, MD).

\section{Western blot analysis}

Western blotting was performed as previously described. ${ }^{22}$ Band images were detected by a LAS 1000 mini system (Fuji Film, Kanagawa, Japan) and densitometric analyses were performed using Image Gauge (Fuji Film). Proteins were standarized against the level of actin protein.

\section{Cell Viability Testing, Tumor formation}

Trypan blue exclusion was performed to ascertain cell viability. Cells were stained with $0.4 \%$ trypan blue (Kanto Chemical Co., Inc. Tokyo, Japan) and then examined microscopically using a hemocytometer to determine the total number of cells and the number of dead cells i.e., those retaining trypan blue. Four representative squares of each slide, $\sim 200$ cells, were assessed and the mean was calculated. Immunodeficient female KSN nu/nu mice were used (Japan SLC, Inc., Shizuoka, Japan). Cells were diluted to $5 \times 10^{6}$ per $100 \mu$ in PBS per mouse, and injected subcutaneously (s.c.) into the backs of mice consisting of groups comprising two mice. External tumor growth was assessed every 5 days. The animal experiments were conducted under the guidelines for the use of experimental animals laid down by the Institute for Genetic Medicine, Hokkaido University.

\section{Motility and invasion assays}

Phagokinetic migration assay ${ }^{27}$ was used to evaluate cell migratory ability. Cells $\left(2 \times 10^{3} /\right.$ well) were plated onto colloidal gold particle-coated coverslips for $24 \mathrm{hrs}$ followed by fixation with $3.7 \%$ formaldehyde/PBS. In the area where cells migrated during incubation, gold particles removed by the cells could be visualized to ascertain the level of cell motility. Migratory cells at 5 fields were observed and photographed under a light microscope (Nikon, Tokyo, Japan). Phagokinetic migration squares were calculated using an $\mathrm{NIH}$ Image. The migration of cells was determined using the Boyden chamber chemotaxis assay. Cells $\left(2 \times 10^{4}\right)$ in the medium were added to the top chamber of a 24-transwell insert ( $8 \mu \mathrm{m}$ pore size polyethylene-terephthalate (PET) membrane)(BD Biosciences, Bedford, MA) in the presence of fibronectin $(20 \mu \mathrm{g} / \mathrm{ml})$ in the lower chamber. Following $6 \mathrm{hrs}$ incubation at $37^{\circ} \mathrm{C}$ in an atmosphere containing 
$5 \% \mathrm{CO}_{2}$, non-migrating cells were removed with a cotton swab. Living cells that passed through the membrane were counted after fixing with 3.7\% formaldehyde/PBS and Giemsa staining. Cells in 10 fields were counted. Cell invasiveness was assayed in 24-well Biocoat Matrigel invasion chambers coated with laminin, collagen type IV, and other extracellular matrix components derived from mouse sarcomas ( $8 \mu \mathrm{m}$ pore size PET membrane)(BD Biosciences). Cells $\left(2.5 \times 10^{4}\right)$ were plated in the top chamber. The bottom chamber contained $20 \mu \mathrm{g} / \mathrm{ml}$ fibronectin (BD Biosciences) as a chemoattractant. Following 24 hrs incubation, non-invasive cells were removed with a cotton swab. Cells that had migrated through the membrane and stuck to the lower surface of the membrane were fixed with $3.7 \%$ formaldehyde/PBS and stained with Giemsa. For quantification purposes, cells were counted under a microscope across all areas of membrane. Student's t test was used to compare the data. A $p$ value of less than 0.05 was considered as statistically significant.

Phase contrast and indirect immunofluorescence microscopy and flow cytometry of actin polymer

Cells cultured on glass slides in chambers were fixed with $3.7 \%$ formaldehyde/PBS, and then treated with $0.1 \%$ Triton X. F-actin was detected by staining the subconfluent cultures with rhodamine-conjugated phalloidin. Stained cells were visualized by confocal microscopy (Olympus, Tokyo, Japan). Actin polymer status was assessed as previously described ${ }^{28}$ following trypsinization, fixation and staining of cells with rhodamine-phalloidin ( $28 \mathrm{nM}$ final, Cytoskeleton, Denver, CO), and quantified using flow cytometry after gating for forward and side scatter (FACScalibur, Becton Dickinson, San Jose, CA). For indirect immunofluorescence for $\mathrm{E}-$ and N-cadherins, cells plated on coverslips were fixed with $3.7 \%$ formaldehyde/PBS for 20 min, permeabilized with TBS containing $0.1 \%$ Triton $X$ for $10 \mathrm{~min}$, and then blocked with 3\% bovine serum albumin for $10 \mathrm{~min}$. Cells were then incubated with monoclonal anti-E- or anti-N-cadherin antibodies diluted 1:100 and incubated with FITC-conjugated secondary antibody (see above) diluted 1:100 for 60 min. Cells were then examined using a confocal microscope (Olympus).

Reverse transcription-polymerase chain reaction (RT-PCR) analysis.

Total RNA was isolated from each cell line using TRIZOL reagent (Invitrogen, Carlsbad, CA). Total RNA $(2 \mu \mathrm{g})$ was then reverse-transcribed using the Transcriptor First Strand cDNA synthesis Kit (Roche, Mannheim, Germany) with random hexamers. In an effort to identify endogenous Snail gene expression in the cell lines, we designed specific primers representing Snail, Slug, Twist, serum response factor (SRF), p53 and the internal marker GAPDH sequences. The PCR primers used were Snail, forward; 5'-TTC TTC TGC GCT ACT GCT GCG-3' ; reverse; 5'-GGG CAG GTA TGG AGA GGA AGA-3', ${ }^{29}$ SRF, forward; 5' GCT GAC AGG GAC ACA GGT 3' ; reverse; 5' GAA GCT GGT AGG CAG CTG 3'; Slug, forward; 5'-CCT GGT CAAGAA GCA TTT CAA-3' ; reverse; 5'-GCC CCA AAG ATG AGG AGT ATC-3' ; Twist, forward; 5'-AGC TGA GCA AGA TTC AGA CCC TC-3' ; reverse; 5'-CCG TCT GGG AAT CAC TGT C-3' ; p53, forward; 5' ATG ACG GAG GTT GTG AGG 3' ; reverse; 5' ATA GGG CAC CAC CAC ACT 3', and GAPDH, forward; 5'-TGG TAT CGT GGA AGG ACT CAT GAC-3' ; and reverse; 5'-ATG CCA GTG AGC TTC CCG TTC AGC-3'. ${ }^{30}$ The thermal cycle profile consisted of an initial denaturation at $94^{\circ} \mathrm{C}$ for $2 \mathrm{~min}$, followed by 30 cycles consisting of a $30 \mathrm{sec}$ denaturation at $94^{\circ} \mathrm{C}$, a $30 \mathrm{sec}$ annealing of primers at $58^{\circ} \mathrm{C}$ (for Snail, Slug, and Twist), $55^{\circ} \mathrm{C}$ (for SRF and 
p53) or $51^{\circ} \mathrm{C}$ (for GAPDH), and a 1 min extension at $72^{\circ} \mathrm{C}$, followed by a final 7 min extension at $72^{\circ} \mathrm{C}$. The PCR products were then electrophoresed through $1.5 \%$ agarose gels. All reactions were repeated at least twice.

\section{Results}

\section{Establishment of gelsolin-overexpressed and-knockdown clones}

In an effort to determine whether overexpression of gelsolin in MCF10A cells can affect cell phenotype such as cell morphology and motility, we used Flag-tagged human gelsolin to distinguish exogenous gelsolin from the endogenous gelsolin present in MCF10A cells. As a control, MCF10A cells were transfected with Flag neo plasmid vector alone. Several clones derived from cells transfected with ectopic gelsolin were isolated and analyzed by Western blot analysis to confirm the expression of human gelsolin. Gelsolin-overexpressed MCF10A clones (Gsn-10A c1, c2) contained at least five times more gelsolin than parental MCF10A cells or control neo clones (Neo-10A c1, c2) without any detectable change in ß-actin expression (Figure 1A).

To knockdown gelsolin expression, we used two different RNA interference systems. Firstly, MCF10A cells were transfected by electroporation with diced-siRNAs, generated using Dicer enzyme, specific to human gelsolin or to green fluorescent protein (GFP). Western blotting confirmed the repression of gelsolin (Figure 1B). The level of gelsolin in cells that had been treated with gelsolin diced-siRNA were significantly lower than that in wild-type or GFP diced-siRNA treated-MCF10A cells without any detectable change in ß-actin expression 3 days following transfection. Scanning and quantifying the Western blots revealed the degree of protein repression to be ca. $70 \% 3$ days following transfection, but the expression recovered 6 days following transfection (Figure 1B). In the presence of siRNA targeted to gelsolin, cell viability remained the same as that of wild-type MCF10A cells. Secondly, the plasmid-based vector pSilencer 3.0-hygro was used to establish stable gelsolin-knockdown cell lines. MCF10A cells were transfected by electroporation with a vector expressing short hairpin RNA (shRNA) against gelsolin (pSGSN3) or control shRNA (pSGFP), subcloned (shRGsn-10A c1, c5 and c9; siRGFP-10A c8, c9 and $c 10$, respectively) and proteins were harvested and analyzed by Western blotting. The results, shown in Figure 1C, demonstrated that shRGsn-10A c1, c5 and c9 gelsolin protein levels were all significantly reduced by nearly ca. $70 \%$ without any detectable change in $ß$-actin expression by RNA interference using pSGSN3. The shRGFP-10A c8, c9 and c10 gelsolin protein levels, on the other hand, did not change significantly.

\section{Focus formation and EMT in gelsolin knockdown clones}

MCF10A cells expressing ectopic gelsolin, gelsolin diced-siRNA or gelsolin shRNA vector were examined by phase-contrast microscopy and photographed to compare morphologic phenotype (Figure 2). Little or no difference was apparent in Gsn-10A c1 and c2, just as in Neo-10A c1 and c2, compared to parental MCF10A cells which are flat and cuboidal (Figure 2A). No change in morphology or growth characteristics was observed in control MCF10A cells transfected with GFP diced-siRNA (Figure 2B). Interestingly, MCF10A cells that were transfected with gelsolin diced-siRNA were readily identified as rounded and refractile, tended to form 
foci at confluence. shRGFP-10A c8, c9 and c10 grew just as with the parental MCF10A cells, while shRGsn-10A c1, c5 and c9 lost contact inhibition and acquired criss-cross growth properties (Figure 2C, High density).

Additionally, shRGsn-10A c1, c5 and c9, but not shRGFP-10A c8, c9 and c10, rapidly lost their epithelial characteristics: breakdown of cellular junctions and cell dispersal, and adopted an elongated spindle-like shape (Figure 2C, Low density). The observed morphological changes are characteristic of EMT. However, shRGsn-10A c1, c5 and c9 did not affect cell viability in terms of trypan blue exclusion (96\% 97\% to $97 \% \sim 98 \%$ in parental and shRGFP-10A c8, c9 and c10 cells), the population doubling time or colony formation in soft agar assays (data not shown). To examine tumor formation, we injected shRGFP-10A c9 or shRGsn-10A c9 into the backs of syngeneic KSN nu/nu immunodeficient nude mice. The injection of $5 \times 10^{6}$ cells that expressed either GFP shRNA or gelsolin shRNA gave rise to tentatively growing tumors. Five days following injection, tumors formed by shRGsn-10A c9 had reached a diameter of $1 \mathrm{~cm}$, and were significantly larger than those formed by shRGFP-10A c9 (Figure 3A). A derivative derived from the gelsolin-shRNA MCF10A clone c9 (d1) showed epithelial morphology following 4-5 months storage in liquid nitrogen (Figure 3B). Western blot analysis of $\mathrm{d} 1$ revealed that the expression of gelsolin was restored to that of the parental MCF10A cell line (Figure 1C), confirming the relationship between the gelsolin knockdown-induced EMT and gelsolin reduction. Taken together, these results suggested that knockdown, and not overexpression, of gelsolin is capable of inducing the transformed phenotype and an EMT in MCF10A cells.

Enhancement of spontaneous motility and invasiveness in gelsolin knockdown clones

Motile and invasive properties were investigated in an effort to determine whether gelsolin-overexpression or -knockdown is able to enhance motility or invasiveness, and whether the latter clones can induce a functional EMT in MCF10A cells. We initially assayed the effect of gelsolin-overexpression or -knockdown on cell motility using a method that employs glass plates coated with colloidal gold particles as described in Materials and Methods. Gsn-10A c1 and c2 did not show higher motility in comparison with parental and neo-transfected clones in this assay (data not shown). In contrast, shRGsn-10A c1, c5 and c9 exhibited higher motile activity (3 4 fold, $\mathrm{p}<0.005$ ) than shRGFP-10A c8, c9 and c10 (Figure 4A, B). In an effort to gain further insight into the motile properties gained by gelsolin shRNA expression, we also tested MCF10A cell motility using the short-term chemotaxis assay, wherein the ability of single cells to migrate independent of cell interactions and in response to a chemoattractant (fibronectin) was measured. shRGsn-10A c1, c5 and c9 migrated more rapidly (ca. 2 fold) with enhanced motility $(p<0.05)$ compared with shRGFP-10A c8, c9 and c10, consistent with their scattered phenotype (Figure 4C). We then examined the impact of gelsolin silencing on invasiveness of MCF10A cells to extracellular matrix components using a Matrigel invasion chamber. shRGsn-10A c1, c5 and c9 showed much more invasive potential (2 3 fold) than shRGFP-10A c8, c9 and $c 10(p<0.025)$ (Figure 4D). The d1 clone demonstrated similar invasive potential to that of shRGFP-10A c8 and c9. Thus, using three different experimental approaches to measure cell motility and invasiveness, we detected enhanced motility and invasiveness in the gelsolin-knockdown MCF10A clones compared with control GFP-shRNA clones. These findings demonstrated that expression of shRNA gelsolin induced a functional EMT that was accompanied by increased motility and invasiveness in MCF10A cells. 


\section{Markers of EMT in gelsolin knockdown clones}

In an effort to establish the nature of the cytoskeletal reorganization in the EMT induced by expression of stable gelsolin shRNA in MCF10A cells, we employed fluorescent staining with rhodamine-labeled phalloidin to detect polymerized actin. It was shown that gelsolin-knockdown induced increased large actin stress fibers, the elongated, ruffled staining pattern typical of motile fibroblasts, and the formation of actin stress fibers localized in lamellipodia of motile cells in shRGsn-10A c1, c5 and c9, but not in shRGFP-10A c8, c9 and c10 (Figure 5A). F-actin levels were estimated by flow cytometry that quantified the level of rhodamine-phalloidin binding. As expected, gelsolin-knockdown shRGsn-10A c1 and c5 cells displayed $2 \sim 3$ fold of the mean phalloidin fluorescence intensity of parental and shRGFP-10A c9 cells

$(p<0.05)$, consistent with increased F-actin levels (Fig. 5B). The morphological changes characteristic of cells undergoing an EMT are accompanied by a shift in gene expression from an epithelial to a mesenchymal repertoire. ${ }^{31-33}$ E-cadherin is involved in promoting and maintaining cell-cell adhesion. ${ }^{34}$ Breakdown of these contacts is a prerequisite for cell dissociation. We therefore characterized the cellular staining pattern of E-cadherin in shRGsn-10A c1, c5 and c9. As shown in the immunofluorescence analysis using anti-cadherin antibodies (Figure 5C, D), shRGFP-10A c8, c9 and c10, which possessed an epithelial-like morphology, showed homogeneous positive staining of E-cadherin at the membrane but no $\mathrm{N}$-cadherin staining at cellular junctions, just as in the parental MCF10A cells. In contrast, shRGsn-10A c1, c5 and c9, which possessed a fibroblast-like morphology, lost or reduced $\mathrm{E}$-cadherin and expressed $\mathrm{N}$-cadherin at the membrane and cytoplasm. Immunoblotting using antibodies that distinguish $\mathrm{E}$ - and $\mathrm{N}$-cadherins confirmed that, unlike shRGFP-10A c8, c9 and c10, shRGsn-10A c1, c5 and c9 exhibited a loss of E-cadherin (20 110 fold) (Figure 6A). In contrast, whereas $\mathrm{N}$-cadherin was absent in parental MCF10A cells and in shRGFP-10A c8, c9 and c10, it was highly expressed in shRGsn-10A c1, c5 and c9 (30 50 fold). This E- and N-cadherin conversion was not observed in the d1 clone.

Cell migration is regulated by pathways that involve cytoskeletal rearrangements resulting in membrane ruffling, lamellae formation and cell protrusions. These cellular activities are controlled by RHO-like GTPases such as RHO, RAC and CDC42. In an effort to determine whether functional changes in cell motility by gelsolin shRNA expression in MCF10A cells may be related to the activity of RHO GTPases, gelsolin shRNA expressing and GFP shRNA control cells were subjected to Western blotting and examined for RAC expression. The results showed that unlike shRGFP-10A c8, c9 and c10, shRGsn-10A c1, c5 and c9 exhibited enhanced expression of RAC compared with control cells (Figure 6A). Overexpression of human-activated proto-oncogene RAS in MCF-10A cells leads to in vitro transformation of the cells ${ }^{35}$ and oncogenic RAS is able to induce morphological transformation of epithelial cells resulting in EMT. ${ }^{36,37}$ We then investigated the association of RAS oncogene pathways (Figure 6B). It was found that the expression of RAS protein, and its mediators (total ERK-1, ERK-2, and phosphatidylinositol 3-kinase (PI3K) proteins) were not enhanced but rather reduced or remained unchanged in shRGsn-10A c1 and c5 in comparison with shRGFP-10A c8. However, the level of phosphorylated ERK (pERK), phosphorylated AKT (pAKT-Ser573), markers of ERK and AKT activation in addition to total AKT (tAKT) was higher in shRGsn-10A c1 and c5 cells in comparison with parental and shRGFP-10A c8 cells. The inhibition of GSK3, which 
plays an important role in EMT induction, ${ }^{38,39}$ was also investigated. Western blot analysis using antibodies against total GSK3 and phosphorylated GSK3 confirmed that the enzyme was being highly phosphorylated in shRGsn-10A c1 and c5 cells but not in parental and shRGFP-10A c8 cells (Figure 6B). Taken together these results suggested that gelsolin knockdown may enhance inactivation of GSK3 activity via ERK- and PI3K-AKT-activation. Additionally, expression of gelsolin shRNA was associated with a reduction in the epithelial markers alpha- $(10 \sim 50$ fold $)$, beta- (10 fold) and gamma (3 7 fold) -catenins, and enhancement of mesenchymal marker fibronectin (300 700 fold) in shRGsn-10A c1 and c5 in comparison with parental MCF10A cells and in shRGFP-10A c8 (Figure 6B). The switch between E- and $\mathrm{N}$-cadherin expressions suggested that gelsolin-knockdown affected not only morphology, but also gene transcription or protein expression of cadherins and catenins in MCF10A cells.

Increased expression of Snail in gelsolin-knockdown clone

Snail family proteins act as suppressive transcriptional factors of E-cadherin. ${ }^{40}$ We explored the expression of three EMT-regulating transcription factors (Snail, Slug, and Twist) and other transcription factors including SRF and p53 in MCF10A cells in an effort to identify their role in EMT and cadherin-mediated switch from E- to $\mathrm{N}$-cadherin using the RT-PCR assay and employing the GAPDH housekeeping gene as the internal control. Expression of Snail was induced in shRGsn-10A c1 and c5 but not in shRGFP-10A c9 and lost in d1 clone (Figure 7). No changes were observed in Slug, Twist, SRF or p53 transcripts. The data implied that Snail is the more likely in vivo repressor of E-cadherin transcription and suggested that activation of Snail expression plays an important role in EMT in gelsolin-knockdown MCF10A clones.

\section{Discussion}

Confirmation of gelsolin as a tumor suppressor

Introduction of three genes encoding the SV40 large-T antigen, the telomerase catalytic subunit and an H-RAS oncoprotein into primary human mammary epithelial cells resulted in cells that form tumors when transplanted into nude mice. ${ }^{41}$ Overexpression of human or rat-activated proto-oncogenes $\mathrm{c}-\mathrm{H}-\mathrm{RAS}$ or c-ERBB-2, or the human transforming growth factor-alpha (TGF-alpha) gene in MCF-10A cells lead to the in vitro transformation of these cells. ${ }^{35}$ MCF-10A TGF-alpha and MCF-10A $\mathrm{H}-\mathrm{RAS}$ cells infected with a retroviral vector containing human c-ERBB-2 were able to grow as tumors in vivo when injected into nude mice. ${ }^{35}$ In our present report, we were interested in determining whether siRNA of a tumor suppressor gelsolin could transform MCF10A mammary epithelial cells by knockdown endogenous expression of gelsolin. This was achieved by transfecting MCF10A cells with a diced gelsolin siRNA or an expression vector carrying gelsolin shRNA. Growth kinetics indicated that loss of contact inhibition and criss-cross-type growth or even foci formation was observed in gelsolin-knockdown MCF10A cells. Furthermore, enhanced temporal growth was demonstrated in immunodeficient mice. Such changes concerning cell growth were not observed in gelsolin-overexpressed clones. These findings strongly confirmed the tumor suppressive activity of gelsolin in human mammary epithelial cells. 


\section{EMT induced by gelsolin-knockdown}

Female mice with a targeted deletion of the gelsolin gene possess defects in mammary gland morphogenesis and indicated that gelsolin is required in the mammary stroma for proper ductal morphogenesis. ${ }^{42}$ The process of tumor invasion is frequently associated with the loss of epithelial markers and the acquisition of mesenchymal markers, including migratory and motile behavior, referred to as EMTs. ${ }^{31-33}$ The EMT concept provides a new means of identifying genes that are important for the progression of carcinoma towards a dedifferentiated and more malignant state ${ }^{33}$ In breast cancer, EMT has been estimated to occur in ca. $20 \%$ of tumors in vivo, ${ }^{43}$ and cytochemical evidence of an EMT was demonstrated following breast carcinoma biopsy. ${ }^{44}$ It is known that elevation or activation of oncogenic signal transduction proteins including RAS, SRC, AKT and TGF- $\beta$ may contribute to tumor spread via promotion of the mesenchymal phenotype. ${ }^{36,37,45-48}$ In the present study, we demonstrated that by knockdown endogenous expression of gelsolin, MCF10A cells showed conversion between epithelial- and mesenchymal-like phenotypes characteristic of an EMT with enhanced motility and invasiveness, as determined by application of three methodologies. However, we did not observe overproduction of RAS or reduced expression of gelsolin in TGF-B-induced EMT in MCF10A cells (not shown). This suggested that RAS and TGF- $B$ proteins are not responsible for the present EMT. The different behavior of gelsolin observed in different cell lines may be linked to the nature of the cells (fibroblastic or epithelial), culture conditions or cytoskeletal organization. Notwithstanding this possibility, these results suggested that silencing, rather than overexpression, of gelsolin leads to increased motility and invasiveness at least in the MCF10A mammary cell line.

\section{Molecules associated with gelsolin-knockdown-induced EMT}

Studying the cellular biology of EMTs might provide insight into the mechanisms of tumor progression. ${ }^{33}$ Recent research conducted in embryonic model systems and in transformed cell lines identified several signal-transduction pathways associated with EMTs. These include remodeling of the actin cytoskeleton and the modulation of adhesion systems, leading to the mesenchymal phenotype and the scattering of carcinoma cells, and the activation of several receptor tyrosine kinases. ${ }^{33}$ In our present experiments, gelsolin-knockdown MCF10A clones showed increased amounts of F-actin in stress fibers and lamellipodia. ${ }^{49}$ These findings may be due to reduced severing and capping functions of gelsolin by its shRNA.

Members of the RHO family are involved in regulatory mechanisms controlling growth and organization of actin microfilaments. Effects include induction of membrane ruffling and cell motility by RAC, which regulates lamellipodia formation through activation of the phospholipid metabolism that generates $\mathrm{PI}(4,5)-\mathrm{P} 2$, which in turn regulates several actin regulatory proteins such as gelsolin. ${ }^{50}$ Fibroblasts from the gelsolin-null mice displayed a five-fold increase in the expression of RAC, where the motility defect and RAC overexpression was repaired following gelsolin transfection. ${ }^{51}$ On the other hand, activation of RAC promotes motility and invasion of mammary epithelial cells on collagen matrices. ${ }^{52}$ In the present report, we also demonstrated that enhancement of both RAC expression and motility was induced by gelsolin shRNA in MCF10A cells. Mitogen-activated protein kinase cascades involving ERK or PI3K activities are likely to be needed to maintain EMT for RAS and TGF- $\beta$. ${ }^{36,37,47,48}$ In the present report, gelsolin-knockdown MCF10A clones that lost their epithelial characteristics and underwent EMT showed enhanced production of activated ERK 
and activated AKT proteins. RAC, and not RAS, protein was overproduced in the gelsolin-knockdown MCF10A clones. This suggested that RAC may play a critical role in activation of the ERK signaling pathway as in the case of cells stimulated by tumor necrosis factor alpha. ${ }^{53}$ These signaling pathways downstream of RAC might mediate the gelsolin shRNA-induced EMT in MCF10A cells. Phosphorylated ERK and phosphorylated AKT might inhibit the activity of GSK3 which leads to a reduction in E-cadherin expression, transition to a more mesenchymal morphology, and transcriptional stimulation of the Snail transcription factor in EMT. 38, 39, 54, 55 Inactivation of GSK3 was observed in the gelsolin knockdown MCF10A cells. This suggested that GSK3 inhibition plays an important role in the gelsolin silencing-induced EMT of human mammary epithelial cells.

\section{Cadherin switch by gelsolin-knockdown}

The cadherins are a family of adhesion molecules that play an important role in embryonic morphogenesis and the formation of solid tissues, a role derived from the multiple functions of these molecules in cell adhesion, signaling, cellular proliferation and differentiation. ${ }^{34}$ Loss of E-cadherin expression or function by mechanisms that include mutational inactivation of E-cadherin or catenin genes, transcriptional repression, or proteolysis of the extracellular domain in epithelial carcinomas, has been thought as the main reason for the disruption of tight epithelial cell-cell contacts, leading to the progression of tumors to an invasive/metastatic state. ${ }^{56}$ In several cancer types, loss of E-cadherin function is accompanied by a gain in the expression of mesenchymal cadherins, such as $\mathrm{N}$-cadherin, in a process that is known as the cadherin switch. ${ }^{56-58}$ Cadherins appear to directly affect the function of each other. Forced expression of $\mathrm{N}$-cadherin in epithelial-like cells resulted in downregulation of E-cadherin and the acquisition of an invasive phenotype. ${ }^{56-58}$ Human breast cancer cells transfected with $\mathrm{N}$-cadherin showed increased motility and metastatic potential. 56, 59 Although the functional implication of this cadherin switch for tumor progression remains unknown, the expression of $\mathrm{N}$-cadherin during tumor progression might be equally necessary and sufficient to overcome E-cadherin-mediated cell-cell adhesion and to promote malignant tumor progression. Gelsolin spatially colocalizes to, and is transiently associated with cadherin adhesion complexes in fibroblasts. ${ }^{60}$

Our present analysis of gelsolin knockdown in MCF10A cells suggested that gelsolin is necessary for actin assembly at cadherin contacts. Furthermore, the knockdown of gelsolin induced the cadherin switch that resulted in a reduction in E-cadherin with concomitant low expression of alpha-, beta- and gamma-catenins as a secondary consequence of the downregulation of E-cadherin and enhanced expression of $\mathrm{N}$-cadherin. Gelsolin may then act as a negative regulator in cadherin contacts, coupling adhesion to actin dynamics, cell signaling and junctional assembly. This confirmed that the contribution of gelsolin to cadherin function involves a specific pool of cadherin molecules. ${ }^{61}$ We also showed that expression of RAC in gelsolin shRNA-MCF10A cells was enhanced with an EMT and the cadherin switch. Sustained RAC activation was sufficient to disassemble cadherin-mediated contacts in keratinocytes. ${ }^{62}$ Regulation of endocytosis may be one mechanism by which RAC could participate in the disruption of cadherin-dependent adhesion. ${ }^{63}$ These findings suggested that RAC might play an important role in the cadherin switch of gelsolin-knockdown-mediated EMT in MCF10A cells. The inhibition of GSK3 can involve beta-catenin up-regulation. Two possibilities, both of which might be operating, could account for the low production of beta-catenin in the gelsolin knockdown clones. 
The first involves destabilization and/or degradation as a consequence of the down-regulation of E-cadherin, as observed in AKT-induced EMT where beta-catenin was displaced and did not colocalize with E-cadherin. ${ }^{46}$ The second involves a GSK3-independent degradation mechanism, for example in the form of a SIAH-1-mediated pathway. ${ }^{64}$

\section{Transcription factor associated with gelsolin-knockdown EMT}

Factors belonging to the Snail family are in fact involved in E-cadherin repression and in EMTs when they are overexpressed in epithelial cell lines, and it has been proposed that these factors act as inducers of the invasion process. ${ }^{40,65}$ Snail expression is inversely correlated with E-cadherin mRNA levels in several epithelial tumor cell lines, such as MDA-MB-435 breast cancer cells that express high levels of Snail, and E-cadherin mRNA could not be detected in these cells. Transfection of Snail into epithelial cells lead to a more fibroblastic phenotype, decreased E-cadherin levels and induced changes resembling an EMT with a scattered, flattened phenotype and low intercellular contacts. ${ }^{60,61}$ Snail not only represses the E-cadherin gene, but might also transactivate other genes such as the gene encoding $\mathrm{N}$-cadherin required for the acquisition of the fibroblastic phenotype. ${ }^{40,65}$ Despite these observations, the molecular mechanisms involved in the repression of E-cadherin by factors of the Snail family and by which the level of other molecules are regulated in EMTs remains poorly understood. ${ }^{40,58}$ In our present experiments, we demonstrated that the expression of Snail was induced, but that of Slug, Twist, SRF or p53, was not changed in gelsolin-knockdown MCF10A cells. The Snail induction might be due to GSK3 inhibition via phosphorylation mediated by ERK- and AKT-activation. 34, 52, 53

The gelsolin-knockdown MCF10A cell lines provide a unique opportunity to investigate the pathogenesis and mechanism of EMT during the progression of human mammary cancers. Additional investigations are currently being performed to delineate the relationship between gelsolin knockdown and EMT induction in an effort to advance our understanding of the tumor progression process.

\section{Acknowledgments}

This research was supported in part by a grant-in-aid from the Ministry of Education, Science, Sports and Culture, Japan and the Sasakawa Scientific Research Grant from the Japan Science Society.

\section{References}

1. Yin HL, Stossel TP. Control of cytoplasmic actin gel-sol transformation by gelsolin, a calcium-dependent regulatory protein. Nature 1979;281:583-6.

2. Sun HQ, Yamamoto M, Mejillano M, Yin HL. Gelsolin, a multifunctional actin regulatory protein. J Biol Chem 1999;274:33179-82.

3. Kwiatkowski DJ. Functions of gelsolin: motility, signaling, apoptosis, cancer. Curr Opin Cell Biol 1999;11:103-8.

4. Chaponnier C, Gabbiani G. Gelsolin modulation in epithelial and stromal cells of mammary carcinoma. Am J Pathol 1989;134:597-603. 
5. Winston JS, Asch HL, Zhang PJ, Edge SB, Hyland A, Asch BB. Downregulation of gelsolin correlates with the progression to breast carcinoma. Breast Cancer Res Treat 2001;65:11-21.

6. Moriya S, Yanagihara K, Fujita H, Kuzumaki N. Differential expression of HSP90, gelsolin and GST- $\pi$ in human gastric carcinoma cell lines. Int J Oncol 1994;5:1347.

7. Furuuchi K, Fujita H, Tanaka M, Shichinohe T, Senmaru N, Ogiso Y, Moriya S, Hamada M, Kato H, Kuzumaki N. Gelsolin as a suppressor of malignant phenotype in human colon cancer. Tumor Targeting 1997;2:277-83.

8. Tanaka M, Mullauer L, Ogiso Y, Fujita H, Moriya S, Furuuchi K, Harabayashi T, Shinohara N, Koyanagi T, Kuzumaki N. Gelsolin: a candidate for suppressor of human bladder cancer. Cancer Res 1995;55:3228-32.

9. Dosaka-Akita H, Hommura F, Fujita H, Kinoshita I, Nishi M, Morikawa T, Katoh $\mathrm{H}$, Kawakami $\mathrm{Y}$, Kuzumaki N. Frequent loss of gelsolin expression in non-small cell lung cancers of heavy smokers. Cancer Res 1998;58:322-7.

10. Lee HK, Driscoll D, Asch H, Asch B, Zhang PJ. Downregulated gelsolin expression in hyperplastic and neoplastic lesions of the prostate. Prostate 1999;40:14-9.

11. Visapaa H, Bui M, Huang Y, Seligson D, Tsai H, Pantuck A, Figlin R, Rao JY, Belldegrun A, Horvath S, Palotie A. Correlation of Ki-67 and gelsolin expression to clinical outcome in renal clear cell carcinoma. Urology 2003;61:845-50.

12. Noske A, Denkert C, Schober H, Sers C, Zhumabayeva B, Weichert W, Dietel $\mathrm{M}$, Wiechen K. Loss of Gelsolin expression in human ovarian carcinomas. Eur J Cancer 2005;41:461-9.

13. Shieh DB, Godleski J, Herndon JE, 2nd, Azuma T, Mercer H, Sugarbaker DJ, Kwiatkowski DJ. Cell motility as a prognostic factor in Stage I nonsmall cell lung carcinoma: the role of gelsolin expression. Cancer 1999;85:47-57.

14. Rao J, Seligson D, Visapaa H, Horvath S, Eeva M, Michel K, Pantuck A, Belldegrun A, Palotie A. Tissue microarray analysis of cytoskeletal actin-associated biomarkers gelsolin and E-cadherin in urothelial carcinoma. Cancer 2002;95:1247-57.

15. Thor AD, Edgerton SM, Liu S, Moore DH, 2nd, Kwiatkowski DJ. Gelsolin as a negative prognostic factor and effector of motility in erbB-2-positive epidermal growth factor receptor-positive breast cancers. Clin Cancer Res 2001;7:2415-24.

16. Cunningham CC, Stossel TP, Kwiatkowski DJ. Enhanced motility in NIH 3T3 fibroblasts that overexpress gelsolin. Science 1991;251:1233-6.

17. Arora PD, McCulloch CA. Dependence of fibroblast migration on actin severing activity of gelsolin. J Biol Chem 1996;271:20516-23.

18. De Corte V, Bruyneel E, Boucherie C, Mareel M, Vandekerckhove J, Gettemans J. Gelsolin-induced epithelial cell invasion is dependent on Ras-Rac signaling. EMBO J 2002;21:6781-90.

19. Tanaka M, Sazawa A, Shinohara N, Kobayashi Y, Fujioka Y, Koyanagi T, Kuzumaki N. Gelsolin gene therapy by retrovirus producer cells for human bladder cancer in nude mice. Cancer Gene Ther 1999;6:482-7.

20. Sazawa A, Watanabe T, Tanaka M, Haga K, Fujita H, Harabayashi T, Shinohara N, Koyanagi T, Kuzumaki N. Adenovirus mediated gelsolin gene 
therapy for orthotopic human bladder cancer in nude mice. $J$ Urol 2002;168:1182-7.

21. Sagawa N, Fujita H, Banno Y, Nozawa Y, Katoh H, Kuzumaki N. Gelsolin suppresses tumorigenicity through inhibiting PKC activation in a human lung cancer cell line, PC10. Br J Cancer 2003;88:606-12.

22. Fujita H, Okada F, Hamada J, Hosokawa M, Moriuchi T, Koya RC, Kuzumaki N. Gelsolin functions as a metastasis suppressor in B16-BL6 mouse melanoma cells and requirement of the carboxyl-terminus for its effect. Int $\mathrm{J}$ Cancer 2001;93:773-80.

23. Zhang J, Hua ZC. Targeted gene silencing by small interfering RNA-based knock-down technology. Curr Pharm Biotechnol 2004;5:1-7.

24. Miller FR, Soule HD, Tait L, Pauley RJ, Wolman SR, Dawson PJ, Heppner GH. Xenograft model of progressive human proliferative breast disease. J Natl Cancer Inst 1993;85:1725-32.

25. Kawasaki $H$, Suyama $E$, lyo M, Taira K. siRNAs generated by recombinant human Dicer induce specific and significant but target site-independent gene silencing in human cells. Nucleic Acids Res 2003;31:981-7.

26. Kuzumaki N, Oda A, Yamagiwa S, Taniguchi N, Kobayashi H, Oikawa T. Establishment of four mouse hybridoma cell lines producing monoclonal antibodies reactive with RAS oncogene product p21. J Natl Cancer Inst 1986;77:1273-79.

27. Albrecht-Buehler G. Phagokinetic tracks of 3T3 cells: parallels between the orientation of track segments and of cellular structures which contain actin or tubulin. Cell 1977;12:333-9.

28. Dhawan J, Helfman DM. Modulation of acto-myosin contractility in skeletal muscle myoblasts uncouples growth arrest from differentiation. Journal of Cell Science 2004; 117: 3735-48.

29. Miyoshi A, Kitajima Y, Sumi K, Sato K, Hagiwara A, Koga Y, Miyazaki K. Snail and SIP1 increase cancer invasion by upregulating MMP family in hepatocellular carcinoma cells. Br J Cancer 2004;90:1265-73.

30. Matsuzaki K, Minami T, Tojo M, Honda Y, Saitoh N, Nagahiro S, Saya H, Nakao M. PML-nuclear bodies are involved in cellular serum response. Genes Cells 2003;8:275-86.

31. Boyer B, Valles AM, Edme N. Induction and regulation of epithelial-mesenchymal transitions. Biochem Pharmacol 2000;60:1091-9.

32. Savagner P. Leaving the neighborhood: molecular mechanisms involved during epithelial-mesenchymal transition. Bioessays 2001;23:912-23.

33. Thiery JP. Epithelial-mesenchymal transitions in tumour progression. Nat Rev Cancer 2002;2:442-54.

34. Takeichi M. Cadherin cell adhesion receptors as a morphogenetic regulator. Science 1991;251:1451-5.

35. Ciardiello F, Gottardis M, Basolo F, Pepe S, Normanno N, Dickson RB, Bianco AR, Salomon DS. Additive effects of c-erbB-2, c-Ha-ras, and transforming growth factor-alpha genes on in vitro transformation of human mammary epithelial cells. Mol Carcinog 1992;6:43-52.

36. Zondaga GCM, Eversa EE, ten Kloostera JP, Janssena L, van der Kammena RA, Collarda JG. Oncogenic ras downregulates rac activity, which leads to increased rho activity and epithelial-mesenchymal transition. J Cell Biol 2000 ; 149:775-782. 
37. Ward KR, Zhang KX, Somasiri AM, Roskelley CD, Schrader JW. Expression of activated M-Ras in a murine mammary epithelial cell line induces epithelial-mesenchymal transition and tumorigenesis. Oncogene 2004; 23: 1187-96.

38. Zhou BP, Deng J, Xia W, Xu J, Li YM, Gunduz M, Hung MC. Dual regulation of Snail by GSK3-mediated phosphorylation in control of epithelial-mesenchymal transition. Nature Cell Biology 2004; 6, 931-40.

39. Bachelder RE, Yoon SO, Franci C, de Herreros AG, Mercurio AM. Glycogen synthase kinase-3 is an endogenous inhibitor of Snail transcription : implications for the epithelial-mesenchymal transition. J Cell Biol 2005; 168: 29-33.

40. Batlle E, Sancho E, Franci C, Dominguez D, Monfar M, Baulida J, Garcia De Herreros $A$. The transcription factor snail is a repressor of E-cadherin gene expression in epithelial tumour cells. Nat Cell Biol 2000;2:84-9.

41. Elenbaas B, Spirio L, Koerner F, Fleming MD, Zimonjic DB, Donaher JL, Popescu NC, Hahn WC, Weinberg RA. Human breast cancer cells generated by oncogenic transformation of primary mammary epithelial cells. Genes Dev 2001;15:50-65.

42. Crowley MR, Head KL, Kwiatkowski DJ, Asch HL, Asch BB. The mouse mammary gland requires the actin-binding protein gelsolin for proper ductal morphogenesis. Dev Biol 2000;225:407-23.

43. Gilles C, Thompson EW. The epithelial to mesenchymal transition and metastatic progression in carcinoma. The Breast Journal 1996;2:83.

44. Petersen OW, Nielsen HL, Gudjonsson T, Villadsen R, Rank F, Niebuhr E, Bissell MJ, Ronnov-Jessen L. Epithelial to mesenchymal transition in human breast cancer can provide a nonmalignant stroma. Am $J$ Pathol 2003;162:391-402.

45. Avizienyte E, Fincham VJ, Brunton VG, Frame MC. Src SH3/2 domain-mediated peripheral accumulation of $\mathrm{Src}$ and phospho-myosin is linked to deregulation of E-cadherin and the epithelial-mesenchymal transition. Mol Biol Cell 2004;15:2794-803.

46. Grille SJ, Bellacosa A, Upson J, Klein-Szanto AJ, van Roy F, Lee-Kwon W, Donowitz M, Tsichlis PN, Larue L. The protein kinase AKT induces epithelial mesenchymal transition and promotes enhanced motility and invasiveness of squamous cell carcinoma lines. Cancer Res 2003;63:2172-8.

47. Ellenrieder V, Hendler SF, Boeck W, Seufferlein T, Menke A, Ruhland C, Adler G, Gress TM. Transforming growth factor beta1 treatment leads to an epithelial-mesenchymal transdifferentiation of pancreatic cancer cells requiring extracellular signal-regulated kinase 2 activation. Cancer Res 2001;61:4222-8.

48. Bakin AV, Tomlinson AK, Bhowmick NA, Moses HL, Arteaga CL. Phosphatidylinositol 3-kinase function is required for transforming growth factor beta-mediated epithelial to mesenchymal transition and cell migration. J Biol Chem 2000;275:36803-10.

49. Small JV. Lamellipodia architecture: actin filament turnover and the lateral flow of actin filaments during motility. Semin Cell Biol 1994;5:157-63.

50. Hilpela $\mathrm{P}$, Vartiainen MK, Lappalainen P. Regulation of the actin cytoskeleton by $\mathrm{PI}(4,5) \mathrm{P} 2$ and $\mathrm{PI}(3,4,5) \mathrm{P}$. Curr Top Microbiol Immunol 2004;282:117-63.

51. Azuma T, Witke W, Stossel TP, Hartwig JH, Kwiatkowski DJ. Gelsolin is a downstream effector of rac for fibroblast motility. EMBO J 1998;17:1362-70. 
52. Keely PJ, Westwick JK, Whitehead IP, Der CJ, Parise LV. Cdc42 and Rac1 induce integrin-mediated cell motility and invasiveness through $\mathrm{PI}(3) \mathrm{K}$. Nature 1997;390:632-6.

53. Nosaka $Y$, Arai A, Kanda E, Akasaki T, Sumimoto H, Miyasaka N, Miura O. Rac is activated by tumor necrosis factor alpha and is involved in activation of Erk. Biochem Biophy Res Comm 2001; 285:675-9.

54. Eldar-Finkelman $H$, Seger $R$, Vandenheede JR, Krebs EG. Inactivation of glycogen synthase kinase-3 by epidermal growth factor is mediated by mitogen-activated protein kinase/p90 ribosomal protein S6 kinase signaling pathway in NIH/3T3 cells. J Biol Chem 1995; 270:987-90.

55. Salas TR, Reddy SA, Clifford JL, Davis RJ, Kikuchi A, Lippman SM, Menter DG. Alleviating the suppression of glycogen synthase kinase-3beta by AKT leads to the phosphorylation of cAMP-response element-binding protein and its transactivation in intact cell nuclei. J Biol Chem. 2003; 278:41338-46.

56. Hazan RB, Qiao R, Keren R, Badano I, Suyama K. Cadherin switch in tumor progression. Ann N Y Acad Sci 2004;1014:155-63.

57. Van Aken E, De Wever O, Correia da Rocha AS, Mareel M. Defective E-cadherin/catenin complexes in human cancer. Virchows Arch 2001;439:725-51.

58. Cavallaro $U$, Christofori $G$. Cell adhesion and signalling by cadherins and Ig-CAMs in cancer. Nat Rev Cancer 2004;4:118-32.

59. Kim JB, Islam S, Kim YJ, Prudoff RS, Sass KM, Wheelock MJ, Johnson KR. $\mathrm{N}$-Cadherin extracellular repeat 4 mediates epithelial to mesenchymal transition and increased motility. J Cell Biol 2000;151:1193-206.

60. Chan MW, El Sayegh TY, Arora PD, Laschinger CA, Overall CM, Morrison C, McCulloch CA. Regulation of intercellular adhesion strength in fibroblasts. J Biol Chem 2004;279:41047-57.

61. Machesky LM, Insall RH. Signaling to actin dynamics. J Cell Biol 1999;146:267-72.

62. Braga VM, Betson M, Li X, Lamarche-Vane N. Activation of the small GTPase ORac is sufficient to disrupt cadherin-dependent cell-cell adhesion in normal human keratinocytes. Mol Biol Cell 2000;11:3703-21.

63. Lozano E, Betson M, Braga VM. Tumor progression: Small GTPases and loss of cell-cell adhesion. Bioessays 2003;25:452-63.

64. Liu J, Stevens J, Rote CA, Yost HJ, Hu Y, Neufeld KL, White RL, Matsunami N. Siah-1 mediates a novel beta-catenin degradation pathway linking p53 to the adenomatous polyposis coli protein. Mol Cell. 2001;7: 927-36.

65. Nieto MA. The snail superfamily of zinc-finger transcription factors. Nat Rev Mol Cell Biol 2002;3:155-66. 


\section{Figure legends}

Figure 1. Western blot analysis for gelsolin expression in MCF10A cells transfected with ectopic gelsolin, gelsolin diced-siRNA or gelsolin shRNA vector. A. gelsolin overexpression clones; wild-type of MCF10A (WT), Neo-transfected (Neo-10A c1 and c2), ectopic human gelsolin-overexpressed (Gsn-10A c1 and c2). B. gelsolin-knockdown cells; wild-type of MCF10A (WT), GFP diced-siRNA transfected (GFP), gelsolin diced-siRNA transfected (GSN), 3 and 6 days following transfection. C. gelsolin-knockdown clones; wild-type of MCF10A (WT), GFP shRNA vector-transfected (siRGFP-10A c8, c9 and c10), gelsolin shRNA-expressed (shRGsn-10A c1, c5, c9, and a derivative (d1)). ß-actin was used as a loading control.

Figure 2. Effect of gelsolin siRNAs on morphological changes in MCF10A cells. Morphological changes were examined using a phase contrast microscope and photographed. A. Monolayer cultures of MCF10A cells stably expressing ectopic neo or gelsolin genes (X 200). B. Monolayer cultures of MCF10A cells expressing GFP diced-siRNA or gelsolin diced-siRNA are shown. Representative foci were observed in gelsolin diced-siRNA-transfected MCF10A cultures 3 days following transfection (X 200). C. Monolayer cultures of MCF10A clones stably expressing GFP shRNA or gelsolin shRNA. Gelsolin shRNA induced cell dispersion (Low density) and criss-cross growth properties (High density) (X200).

Figure 3. A. Tumor growth from cells transduced with gelsolin targeted shRNA: shGFP-10A c9 (Dotted lines), shRGsn-10A c9 (Solid lines). $5 \times 10^{6}$ cells were injected s.c. into the backs of 2 nude mice. B. Epithelial Morphology of d1 which derived from gelsolin-shRNA MCF10A clone c9.

Figure 4. Enhanced motility and invasiveness in MCF10A clones stably expressing gelsolin shRNA. A. Migration of MCF10A clones expressing gelsolin shRNA on colloidal gold-coated glass plates. The colloidal gold-free areas (black areas) represent the phagokinetic activity of the cells. Left; GFP shRNA clone (X200). Right; gelsolin shRNA clones (X200). B. The data are mean averages + SD of gold particle-free areas (Square pixels). C. Chemotaxis assays using Transwell filters with fibronectin as a chemoattractant. The data are expressed as mean + SD of number of migrated cells/field of view. D. Matrigel-coated membranes used for the invasion assays. The data are expressed as mean + SD of number of migrated cells/membrane of view. All data represent triplicate samples for each experiment utilizing three separate experiments for GFP shRNA- and gelsolin shRNA-transfected MCF10A clones, and a d1 clone.

Figure 5. Immunostaining and flow cytometry of actin and cadherins. A. Reorganization of actin cytoskeleton observed in a GFP shRNA-transfected MCF10A clone (c8, Left) and a gelsolin shRNA-expressing MCF10A clone (c1) (X 400). Phalloidin stained in two patterns: Middle. large actin bundles transversed the cells. Right. the leading edges of lamellipodia were also delineated by a band of $\mathrm{F}$-actin at these cell margins. B. Actin polymer levels. Actin polymer status was estimated using flow cytometry analysis of rhodamine-phalloidin binding in gelsolin shRNA-expressing MCF10A clones (c1 and c5) and a GFP shRNA-transfected MCF10A clone (c9). (Expressed relative to parental MCF10A cells, mean + SD; $n=2$ ). C and D. Effect of 
gelsolin-knockdown on cell surface $\mathrm{E}-$ and $\mathrm{N}$-cadherin levels, respectively. Representative fluorescence photographs of GFP shRNA-transfected (c9) and gelsolin shRNA-expressed (c9) clones stained for E- or N-cadherin (X 400).

Figure 6. Western blot analysis of markers associated with gelsolin knockdown-induced EMT. A. Immunoblots of lysates of a GFP shRNA-transfected MCF10A clone (c8, c9 and c10), gelsolin shRNA-expressing MCF10A clones (c1, c5 and $\mathrm{c} 9$ ), and a derivative (d1). Gelsolin shRNA clones showed reduced levels of E-cadherin, and enhanced levels of $\mathrm{N}$-cadherin and RAC. B. Immunoblots of lysates of a GFP shRNA-transfected MCF10A clone (c8), gelsolin shRNA-expressing MCF10A clones (c1 and $c 5$ ). Gelsolin shRNA clones (c1 and $c 5$ ) showed reduced levels of RAS, ERK-1, PI3K and alpha-, beta- and gamma-catenins and enhanced levels of phosphorylated ERK, phosphorylated AKT(Ser473), total GSK3 (tGSK) and phosphorylated GSK3 (pGSK), and fibronectin. ß-actin is a loading control.

Figure 7. RT-PCR analyses for transcription factors associated with EMT: Snail, Slug, Twist, and controls: SRF and p53 expression in shRGFP-10A c9 and shRGsn-10A c1, $\mathrm{c} 5$, and $\mathrm{d} 1$. The housekeeping gene GAPDH mRNA is shown as an internal control. 
Fig. 1

A

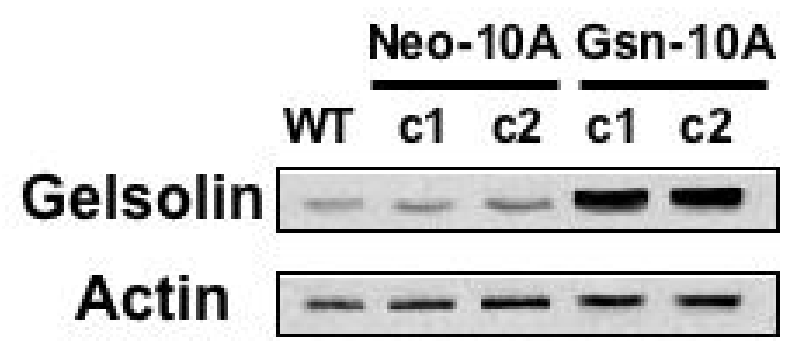

B

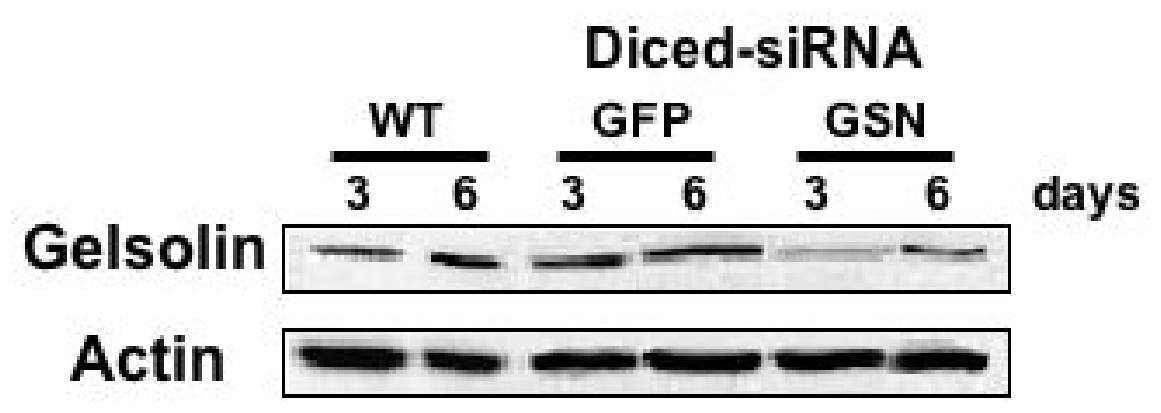

C

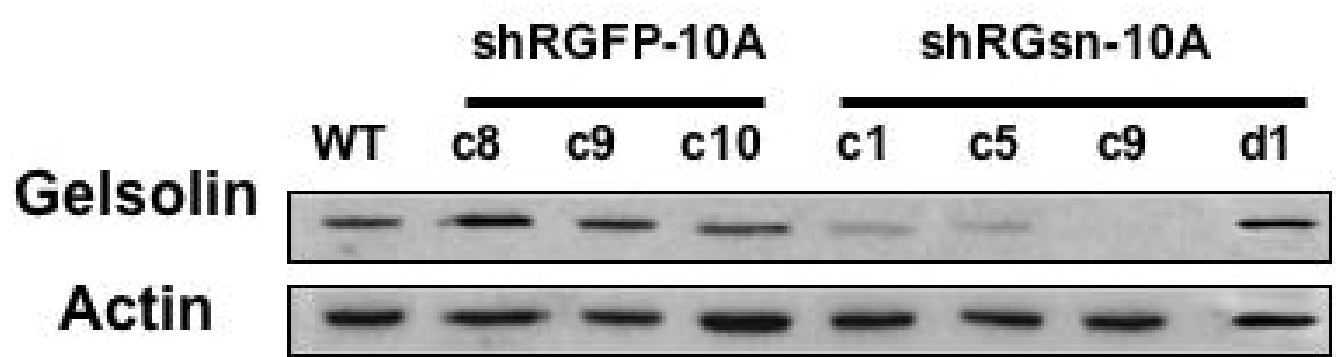


Fig. 2

A
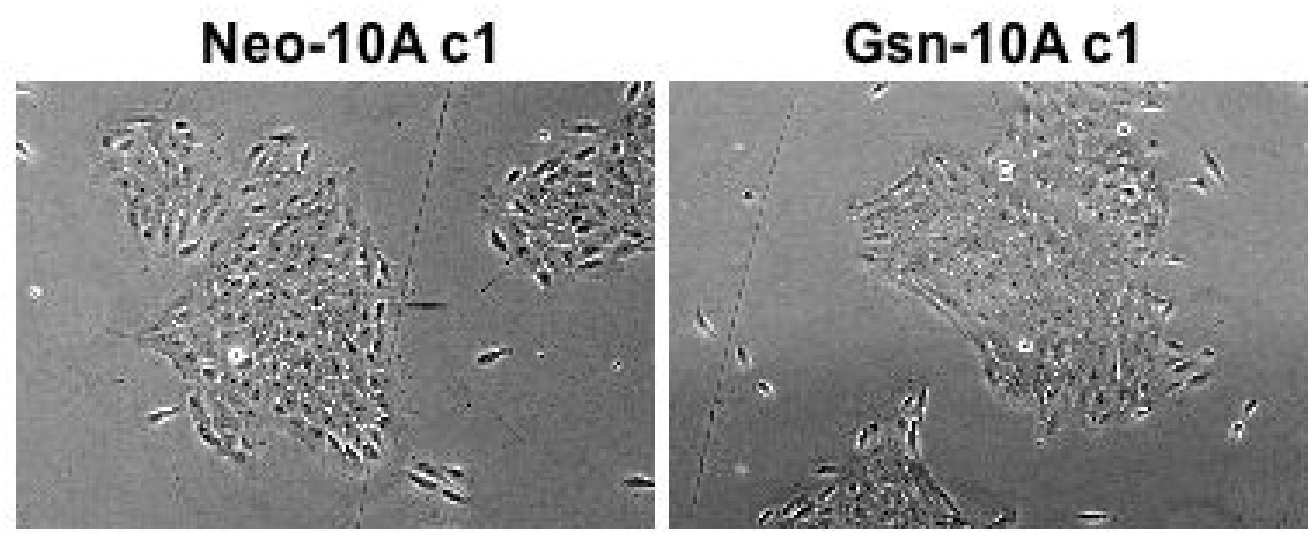

B

GFP diced-siRNA

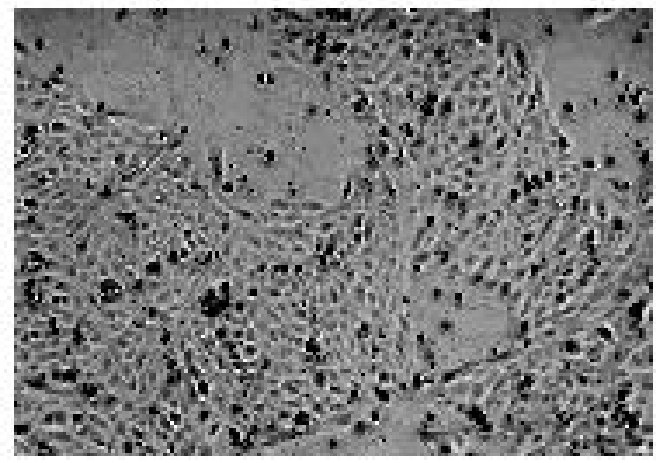

C

Low density

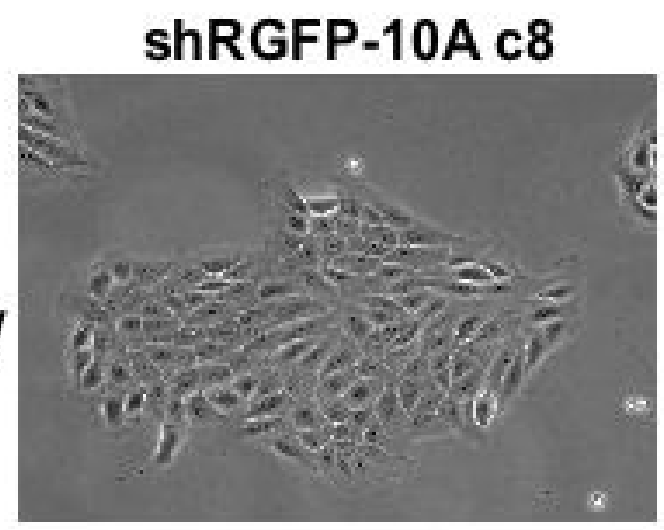

shRGFP-10A c8

High density
GSN diced-siRNA

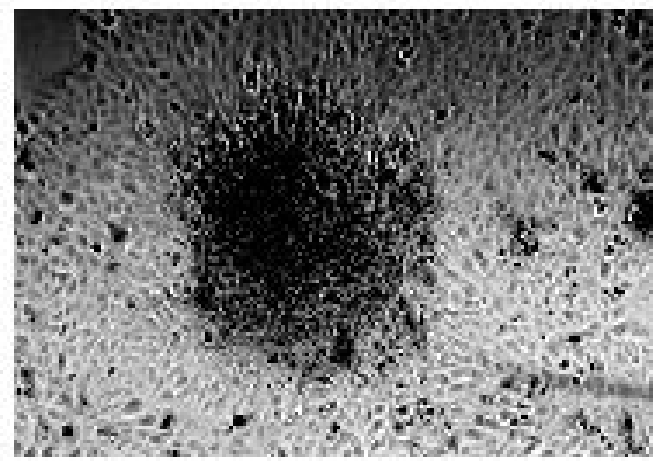

shRGsn-10A c1

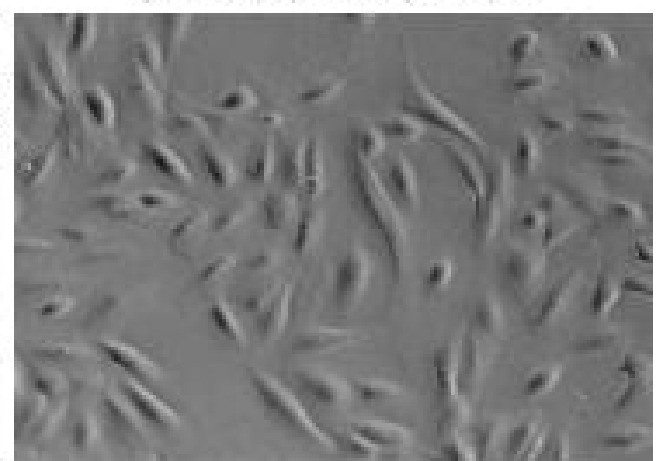

shRGsn-10A c1 
Fig. 3

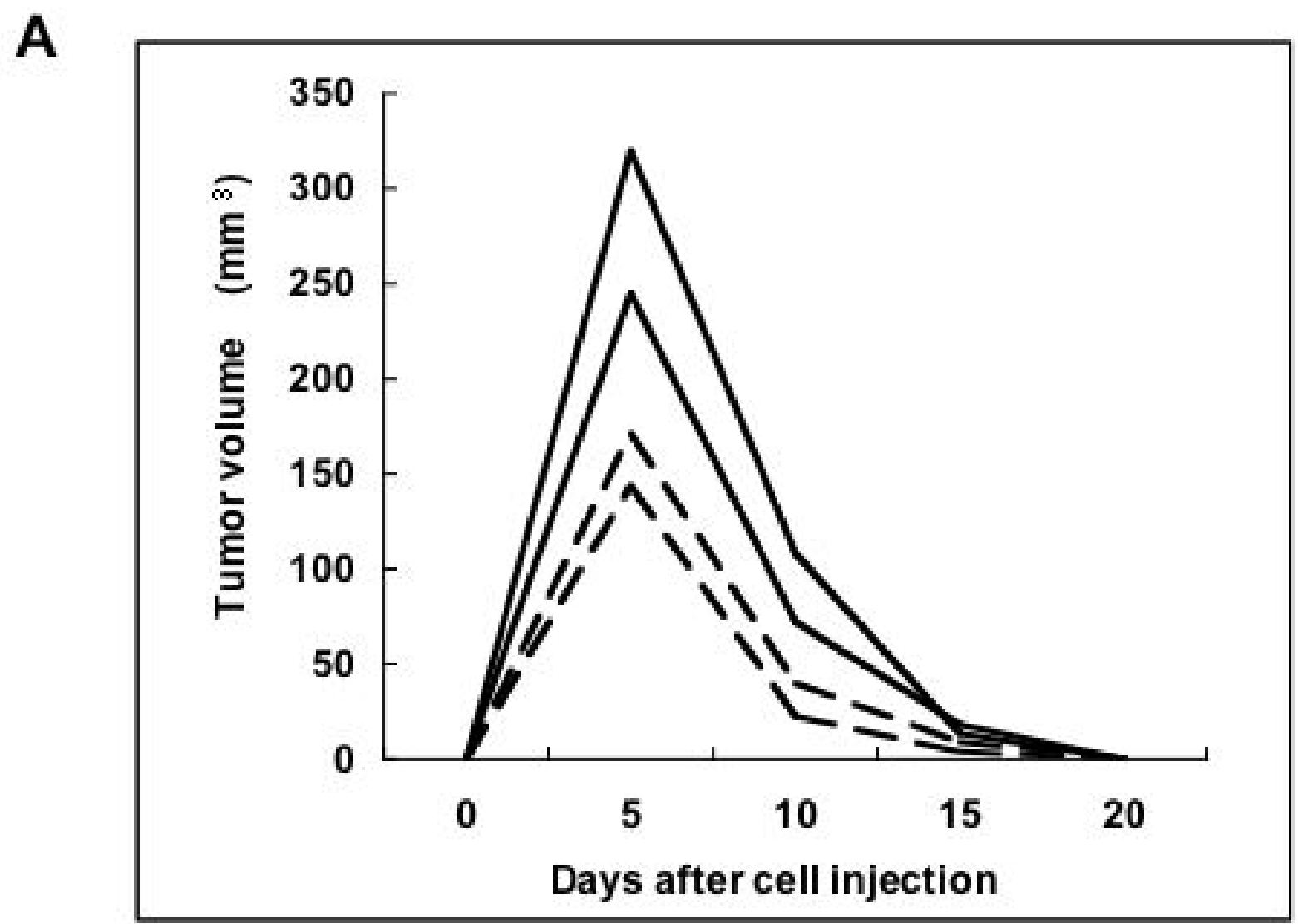

B
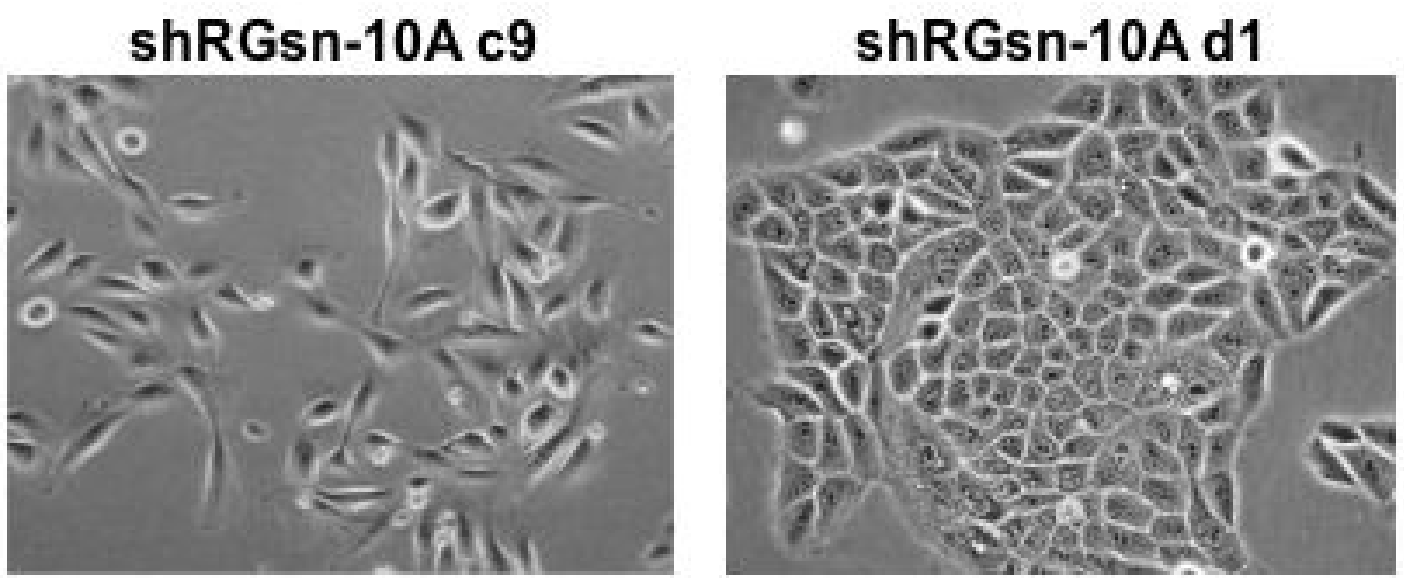
Fig. 4

A

shRGFP-10A c8

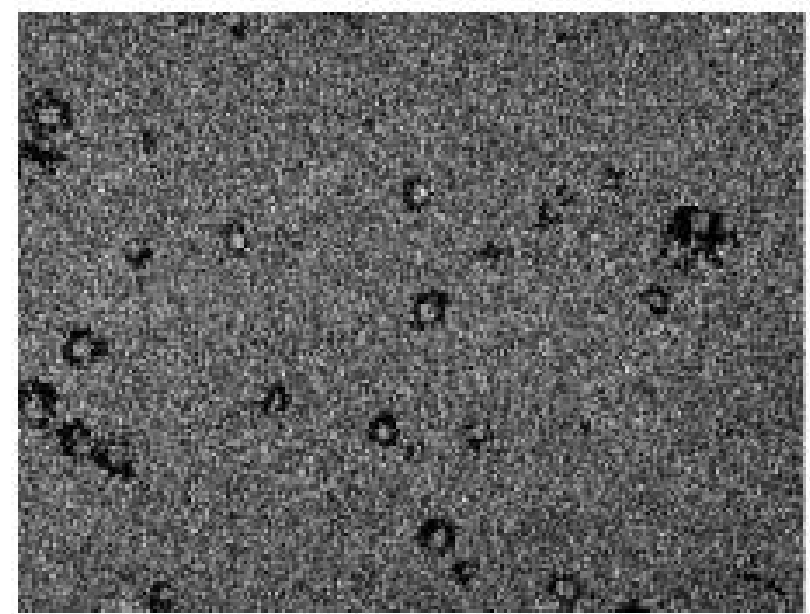

B

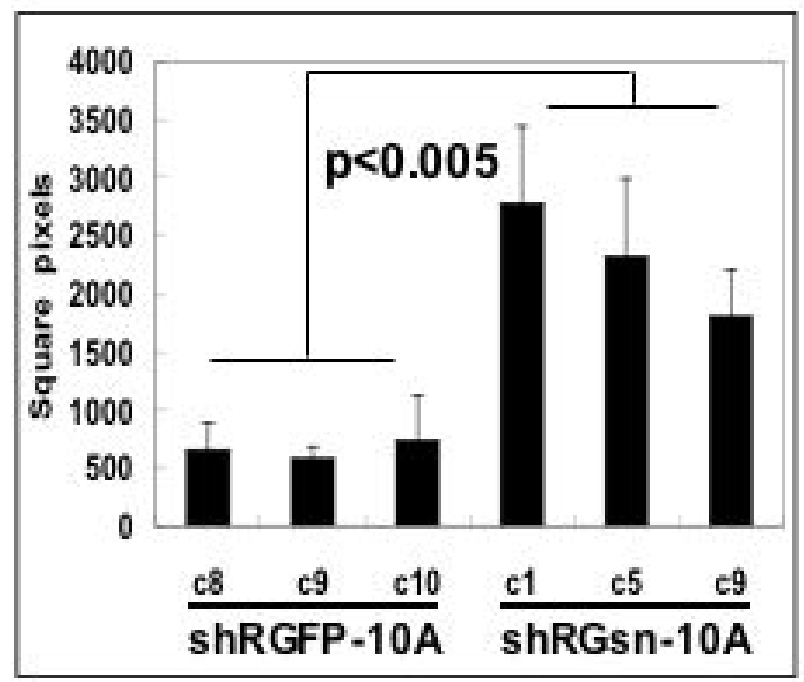

shRGsn-10A c9

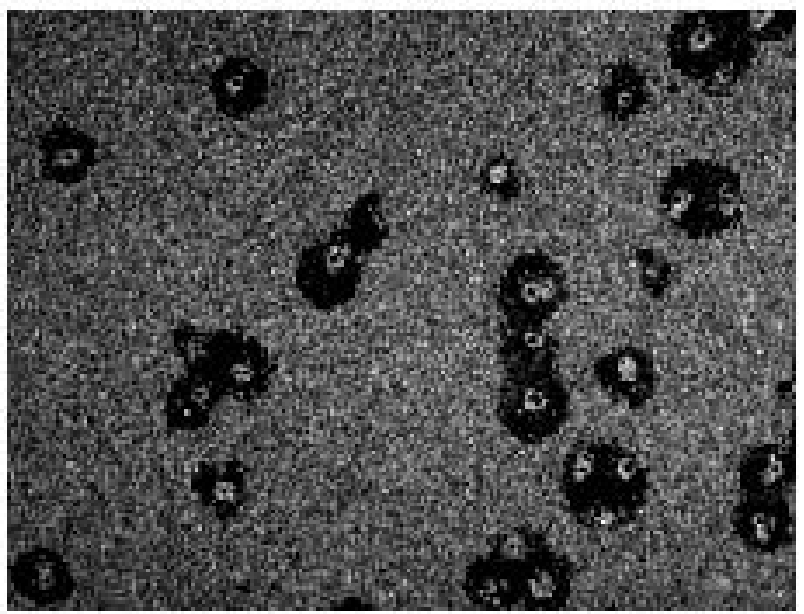

C

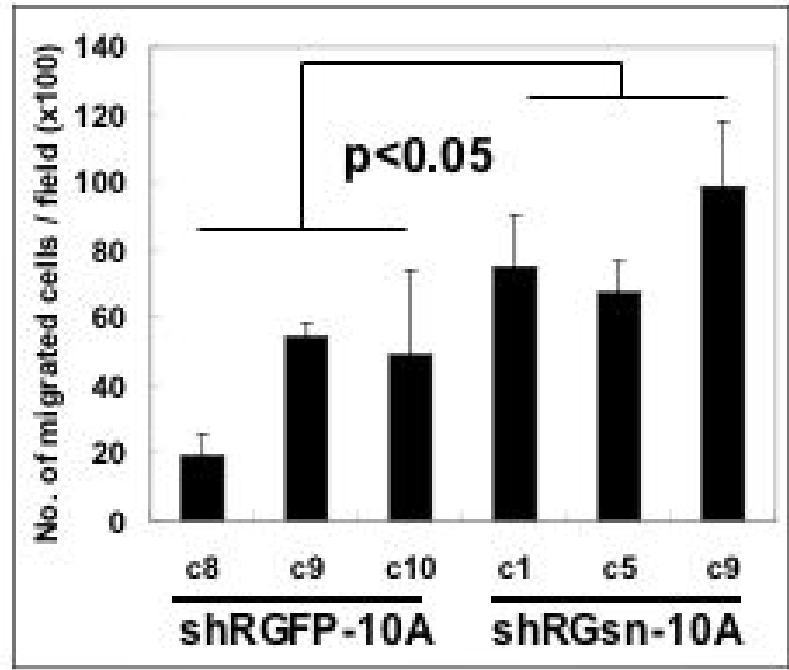

D

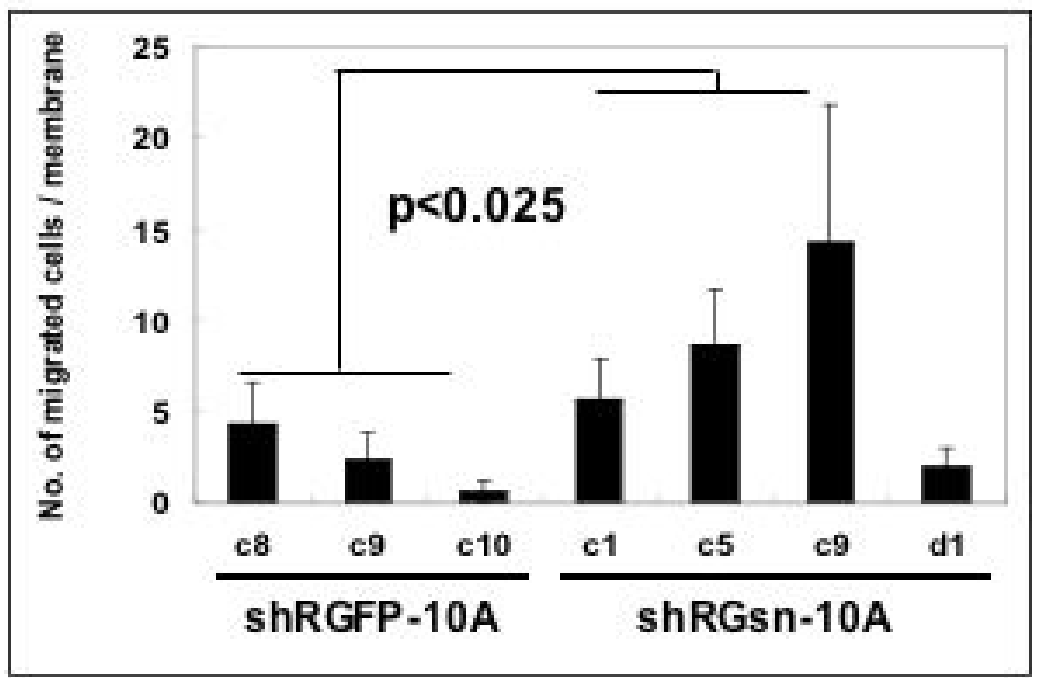


Fig. 5

A

shRGFP-10A c8 shRGsn-10A c1 shRGsn-10A c1
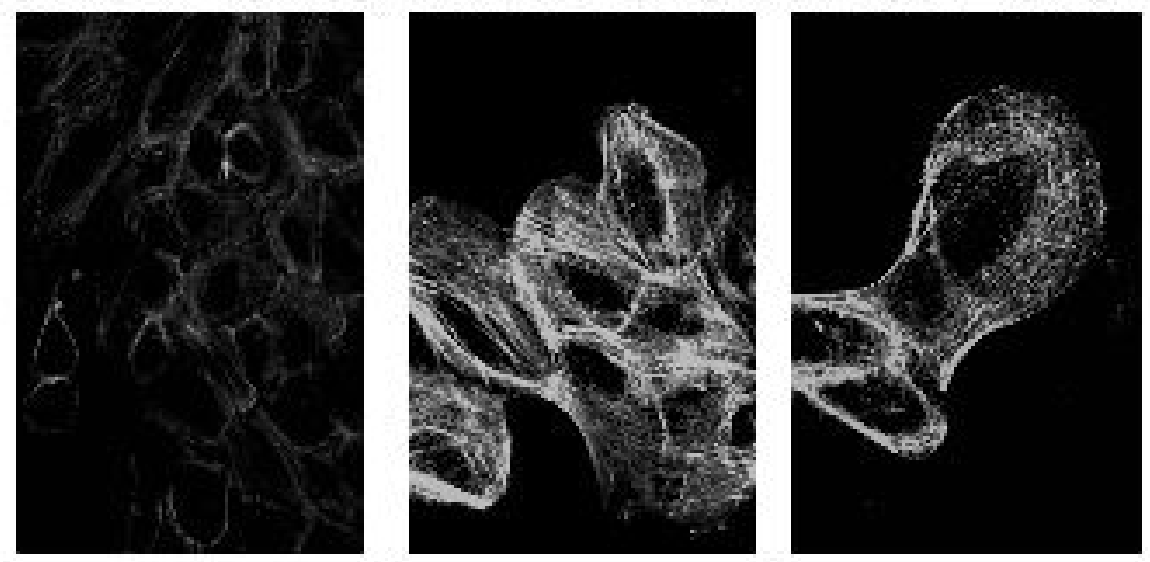

B

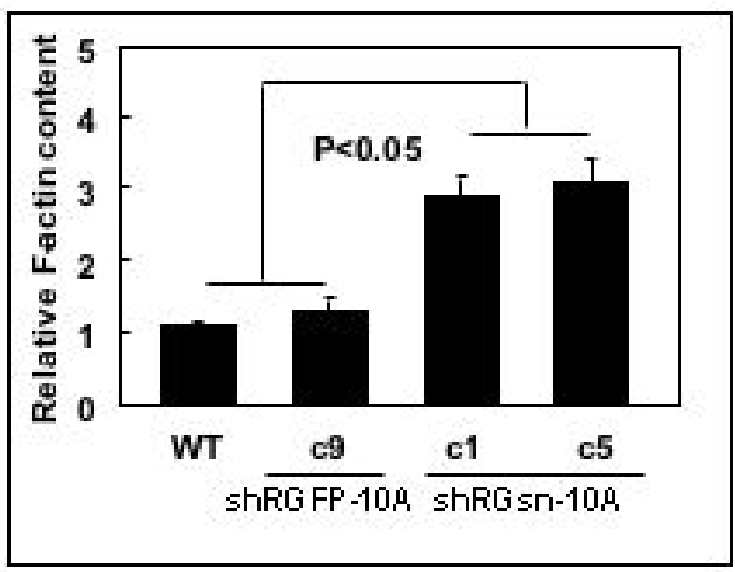

C

MCF10A

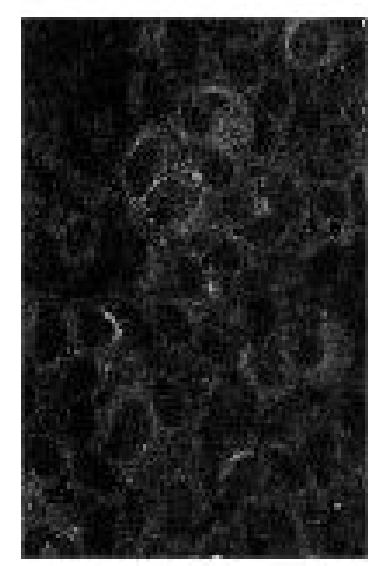

ShRGFP-10A c9

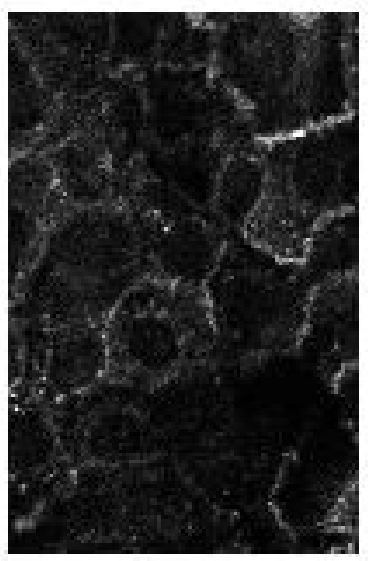

shRGsn-10A c9

D

MCF10A

ShRGFP-10A c9
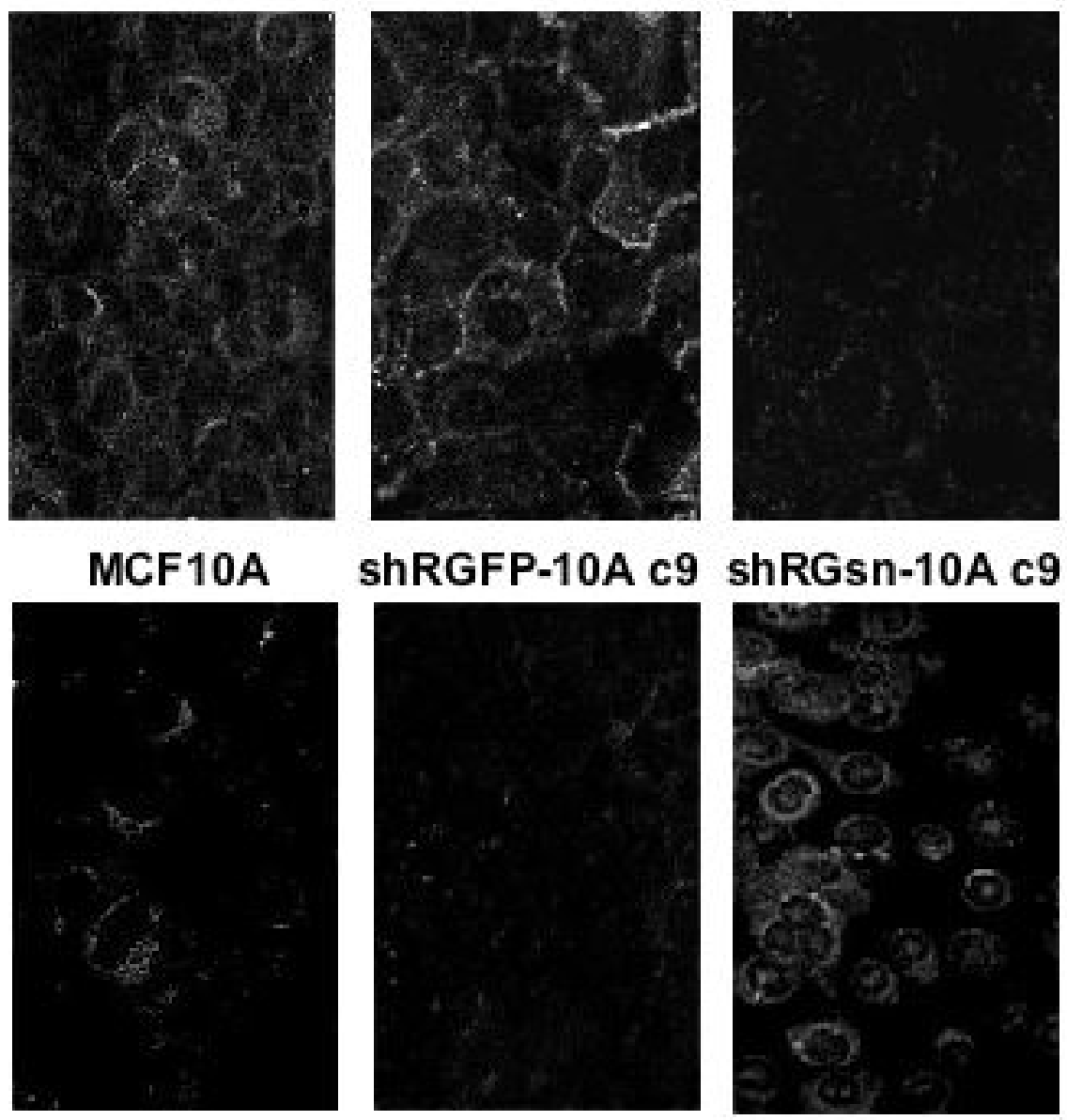

shRGsn-10A c9

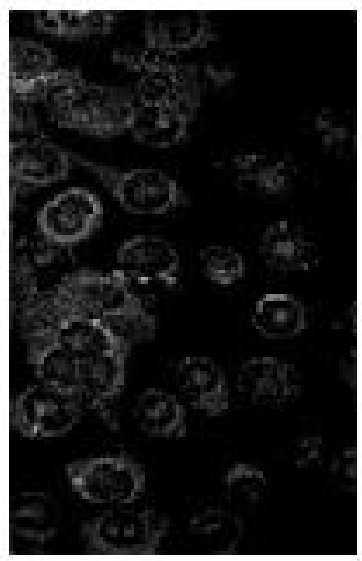


Fig. 6

A

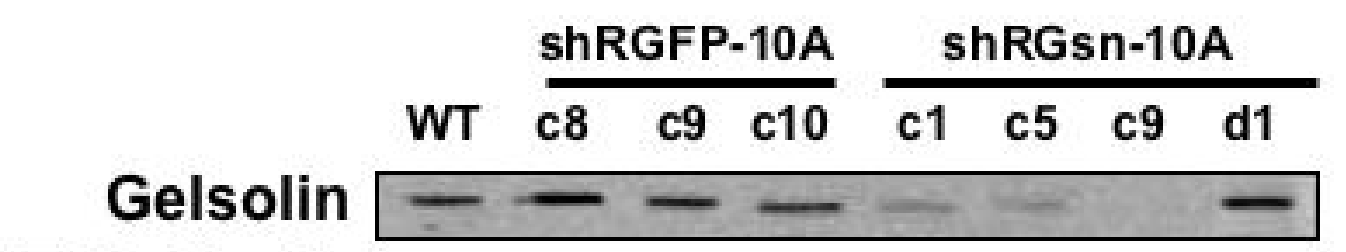

E-Cadherin

$\mathrm{N}$-Cadherin

$-$

Rac

Actin $-\infty-\infty-\cdots$

B

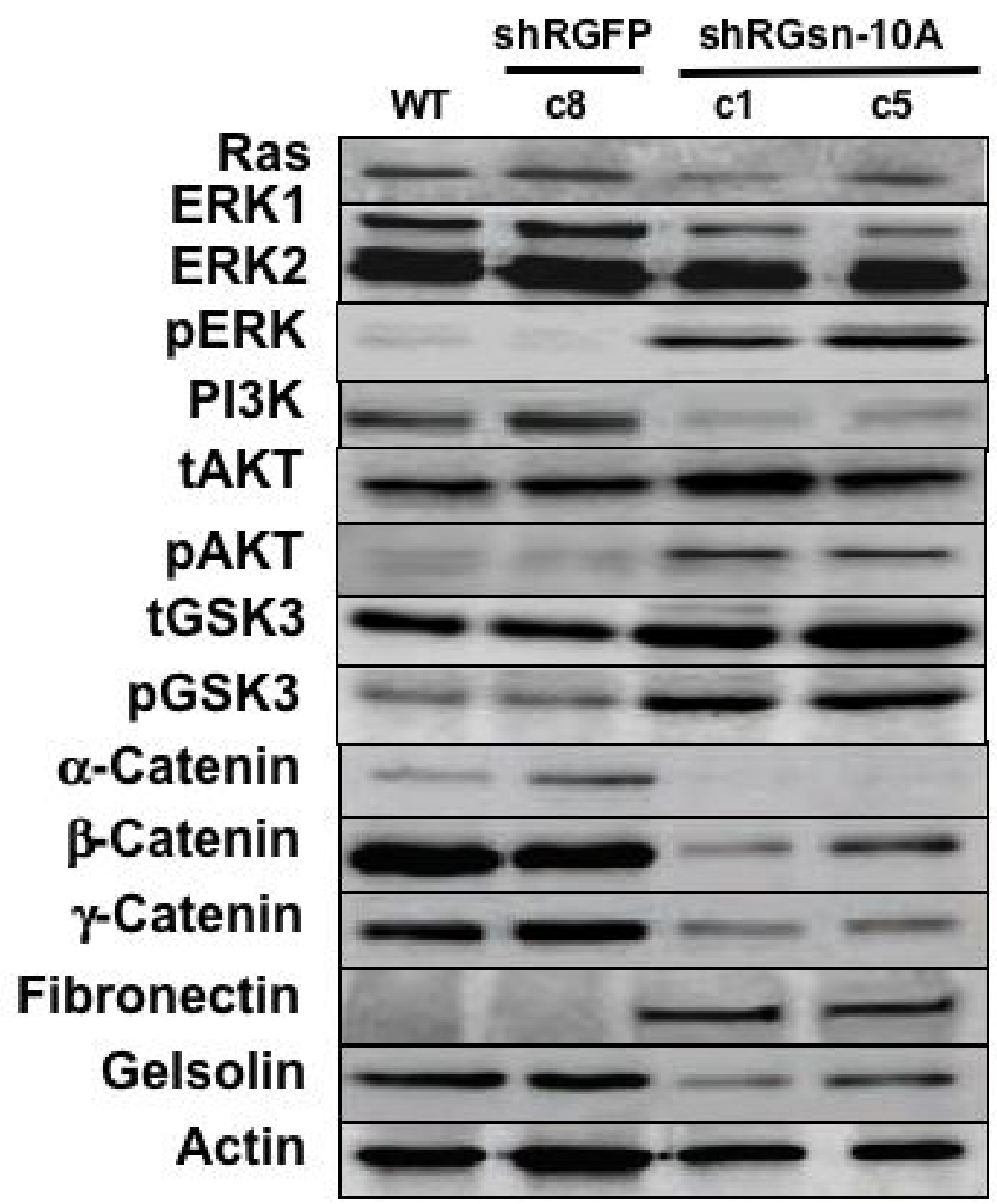


Fig. 7

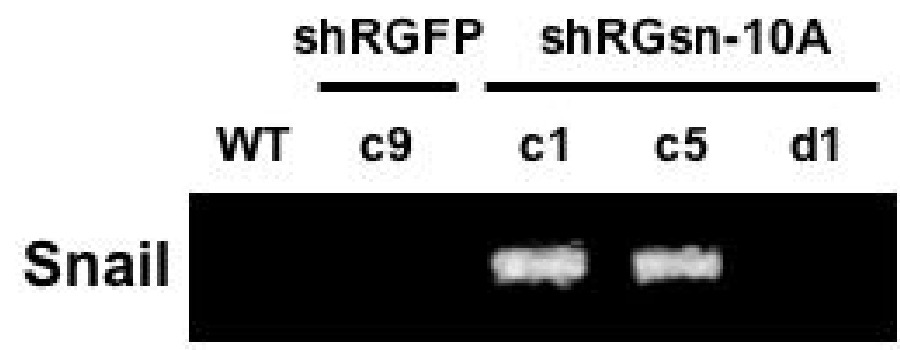

Slug
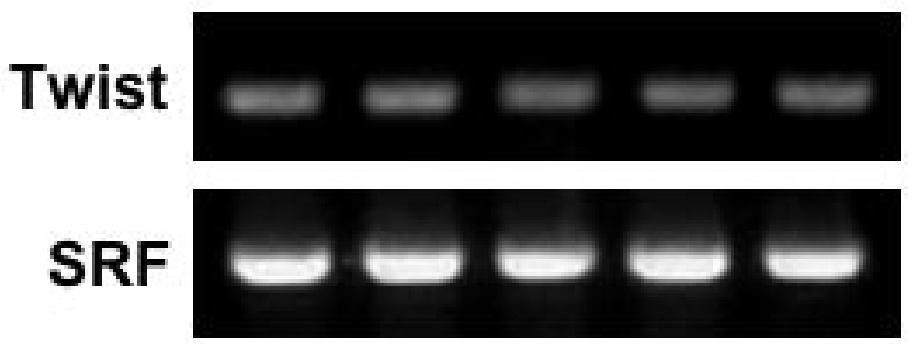
p53
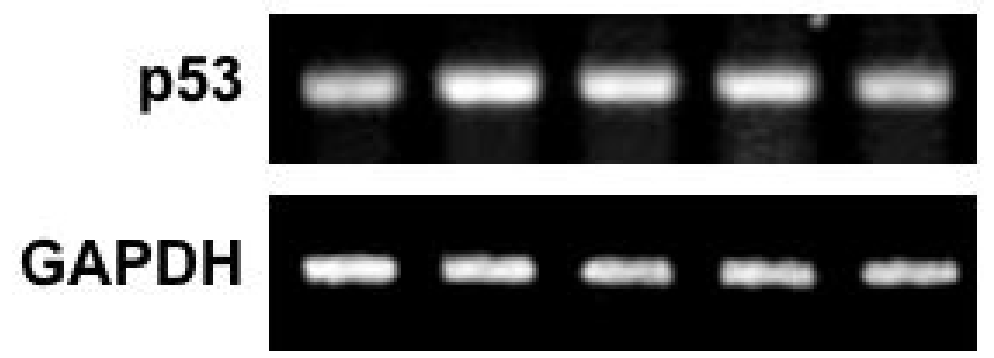